\title{
The ABC's of Ecological and Nutrition Labels. The Impact of Label Theme and Complexity on the Environmental Footprint of Online Grocery Choices
}

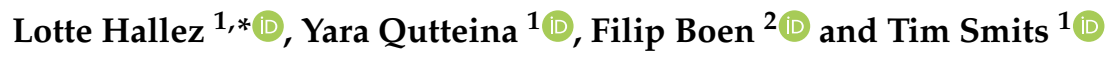 \\ 1 Institute for Media Studies, KU Leuven, 3000 Leuven, Belgium; yara.qutteina@kuleuven.be (Y.Q.); \\ tim.smits@kuleuven.be (T.S.) \\ 2 Physical Activity, Sports \& Health Research Group, KU Leuven, 3001 Leuven, Belgium; \\ filip.boen@kuleuven.be \\ * Correspondence: lotte.hallez@kuleuven.be; Tel.: +32-1619-3481
}

Citation: Hallez, L.; Qutteina, Y.; Boen, F.; Smits, T. The ABC's of Ecological and Nutrition Labels. The Impact of Label Theme and Complexity on the Environmental Footprint of Online Grocery Choices. Sustainability 2021, 13, 2474. https:// doi.org/10.3390/su13052474

Academic Editor: Florian Lange

Received: 16 December 2020

Accepted: 19 February 2021

Published: 25 February 2021

Publisher's Note: MDPI stays neutral with regard to jurisdictional claims in published maps and institutional affiliations.

Copyright: (c) 2021 by the authors. Licensee MDPI, Basel, Switzerland. This article is an open access article distributed under the terms and conditions of the Creative Commons Attribution (CC BY) license (https:// creativecommons.org/licenses/by/ $4.0 /)$.

\begin{abstract}
Current food production and consumption patterns pose serious threats to our global environment. The goal of the current research is to investigate whether the presence of specific informational cues, i.e., ecological labels and nutrition labels, can improve the environmental impact of food choices. Two online experiments were carried out in which young adults were asked to select products in a grocery shop setting, and to indicate quantities (in grams) for a hypothetical one-person meal. In the first experiment $(\mathrm{N}=142)$, we varied the theme (sustainability vs. nutrition vs. control) of the labels alongside the products. The labels displayed a summarized product score (i.e., the products' actual nutri-score), but this was either presented as the nutritional score or as the ecological score of that product. In the second experiment $(\mathrm{N}=250)$, we again varied this label theme as well as the level of complexity, namely interpretative (i.e., simple) vs. reductive (i.e., detailed). While the results of the first experiment revealed no impact of the labels, the results of the second experiment suggest that labels with a sustainability theme can influence young adults to compose a more sustainable meal with less meat, and with a lower carbon and blue water footprint. The labels' level of complexity did not impact the different eating outcomes. In conclusion, while these results point to the potential use of labels with a sustainability theme, it is important to note that the results did not consistently replicate across studies and analyses and should therefore be interpreted with caution. A possible explanation for the effect of eco-themed labels might be that they trigger pro-environmental objectives during decision-making, and prime people to consider the sustainability of their food choices.
\end{abstract}

Keywords: food choices; eco label; nutrition label; environmental impact; online decision task

\section{Introduction}

Food consumption is highly connected to sustainability. Currently, food production is responsible for approximately $26 \%$ of all greenhouse gas emissions, $50 \%$ of the habitable land use and $70 \%$ of the freshwater use [1]. Many authors have stressed the benefits of adopting a diet that is (more) sustainable, i.e., with high quantities of plant-based products and limited quantities of animal-based products (see e.g., [2,3]). Although vegetarian and vegan diets have the greatest environmental benefits, there is also much profit in less drastic shifts in dietary patterns. For instance, an increase in alternative diets, e.g., in which animal and dairy products are partially replaced by plant-based products or in which more sustainable types of meat are included, would already cause significant reductions in the use of land and water, and in the amount of GHG emissions [4]. Therefore, the promotion of such alternative diets should be a central focus to pursue environmental protection.

During recent decades, consumers have shown a growing interest in (protecting) the global environment and an increasing desire to be 'green consumers' [5-7]. Nevertheless, 
the consumption of unsustainable food products such as processed meats and dairy remains high. For instance, European consumers exceed the recommended intakes of these unsustainable food groups established by the World Health Organization [8,9]. Globally, developing countries also see an increase in meat consumption linked with the rise in income per capita [10]. This is also noticeable at the production side, as the supply of meat and dairy products increased considerably between 1961 and 2013 [9]. When asked, young consumers indeed claim that they often do not make sustainable food choices [11]. This gap has been documented in the literature as an attitude-behavior gap [12]: even when people have a positive attitude towards sustainability, they will not necessarily transfer this attitude into sustainable behaviors.

There are a variety of factors that influence (pro-environmental) food decision-making [13]. Much research has been devoted to the role of individual factors, including normative and behavioral beliefs [14], personal values such as egoism, altruism and biospherism [15,16], past consumption behaviors [17], situational factors such as hunger, attitudinal factors related to health and sustainability [18], and demographic variables such as age and gender [13]. While sustainability is a well-established motive for food choices $[19,20]$, it is important that this motive is activated at point-of-purchase [21]. In addition, people are often uninformed about the environmental impact of different food products [19,22,23], and could benefit from informational cues like labels at the point-of-purchase [24]. Labels could thus trigger the right objectives at point-of-purchase and guide people towards the more sustainable choices.

However, most research on labels so far has focused on the impact of nutrition labels which inform about the nutritional value of food products [25]. A number of recent studies have investigated the role of the so-called 'nutri-score' nutrition label. This label, which was introduced in France in 2017, has been officially recommended by several European countries such as France, Belgium, and Spain [26]. It considers a number of nutrients to establish a summary score of a product's nutritional value, which is represented by a color (from green to red) and a letter (from A to E). The nutri-score was found to be a reliable indicator of the nutritional quality [27], with a great potential to influence consumer understanding of product healthiness [28,29]. Moreover, a study by De Temmerman et al. (2020) showed that it can influence healthier eating intentions, and Poquet et al. (2019) demonstrated that it can improve the nutritional value of food choices. Following such promising findings, a range of politicians, public health organizations and food companies have launched a call to make the nutri-score mandatory in all countries in the European Union [30].

The success of the nutri-score label may (partly) be explained by its simple and evaluative nature. In their review, Ikonen et al. (2019) distinguish between reductive labels (e.g., guidelines daily amount label), which provide detailed, factual information on several key nutrients, and interpretative labels (e.g., nutri-score label, traffic light labels), which provide simple, evaluative information about the overall quality of a product. While it is mandatory for manufacturers to include a reductive 'nutrition facts table' on the back of food packages, products often also voluntarily display an interpretative nutrition label on the front of the packaging [31]. A recent systematic review [25] concluded that interpretative nutrition labels more often lead to healthier choices and consumption than reductive nutrition labels. One reason for this finding may be that interpretative labels are better at attracting consumers' attention [32]. Moreover, consumers prefer this type of label, because they find it more appealing and easier to interpret [33].

In comparison, less research to date has focused on the impact of ecological or eco labels which inform about the environmental value of a food product, despite the major prevalence of these types of labels [34,35]. Currently, the use of eco labels is voluntary in the European Union, leading to a range of different labels being used in different countries [31,35]. These labels usually cover only one environmental attribute, such as greenhouse gas emissions, water use, waste, biodegradability, farming method, etc. For instance, the EU has introduced an official 'organic logo' which helps consumers identify products that are strictly organic [36]. To our knowledge, there is currently no formalized 
label available that provides a simple summary of the overall sustainability of a food product (e.g., with a score and/or color). A considerable number of studies have shown that European consumers find the current eco labels confusing and complicated (see e.g., $[11,22,37,38])$. They find it difficult to interpret numbers on eco labels, and to compare the environmental impact of different products [22,39]. In addition, consumers only have limited cognitive capacity, and can get distracted or discouraged when processing a lot of information [40]. The introduction of a single, interpretative eco label would limit the noise in the retail environment, and could aid consumer understanding. Similar to the nutriscore, such a label should consider different values to provide a summary sustainability score and should allow comparison between different food products [11,22,39].

With respect to the impact of eco labels, three experimental studies have found that (fictional) eco labels that present simple and evaluative carbon information can influence more sustainable food choices [24,41,42]. All three studies investigated the impact of one or more carbon labels on the purchase of environmental-friendly products, either in a real store or in an online web shop. To our knowledge, only the studies by Atkinson \& Rosenthal (2014) and by Vlaeminck et al. (2014) have investigated the impact of a (fictional) eco label that displayed a summary sustainability score (from 1 to 10). Whereas the former found no impact of this type of label on purchase intent, the latter found that such a simplified eco label increased the sustainability of food purchases [39,43]. However, the labels were still quite detailed given that they also provided a separate evaluation of different environmental attributes (e.g., GHG emissions, energy use, land use). Given the promising findings concerning the nutri-score label, and given the desire for a similar label format in the sustainability domain [22], studies are needed that investigate the impact of an eco label that uses a simple score and a color scale to evaluate the overall environmental impact of a food product and which allows people to compare between products. Given that such an eco label does not yet exist, the current research takes the first step to investigate the potential impact of an eco-themed equivalent of the nutri-score label. This label was not based on an LCA assessment, so the scores were not a completely accurate reflection of the products' real environmental impact value. Nevertheless, the results may inform researchers and policymakers in the further investigation and development of such a label.

The current research presents two experimental studies that investigated the impact of eco-themed labels and nutrition-themed labels on the sustainability of food choices in an online decision task. Participants were presented with an online grocery scenario, and were asked to select products and indicate quantities for a one-person meal. In the first experiment, the products were presented with (or without) an interpretative label that displayed an evaluative letter score and color. The scores varied between products, but products received the same score on the eco-themed and the nutrition-themed label. The only difference between the labels was thus the label theme (nutrition vs. sustainability). There was also a control condition without labels. We hypothesized that the eco-themed label would lead to more sustainable food choices (i.e., less meat, lower carbon and blue water footprint) compared to no labels. The presence of an eco-themed label might trigger pro-environmental objectives during decision-making, and prime participants to consider the sustainability of their choices. In that case, their choices might be based on the information provided in the labels, but also on their own knowledge and perceptions regarding the sustainability of food products. Given that sustainable choices often are healthier than non-sustainable choices [3], we studied to what extent nutrition-themed labels could influence more sustainable and healthier choices compared to the control situation. In the second study, we included an interpretative (i.e., simple, evaluative) version as well as a reductive (i.e., detailed, factual) version of the eco label and the nutrition label. We again hypothesized that the eco-themed labels would influence more sustainable choices compared to no labels. Furthermore, given the number of studies in the domain of nutrition labels [25], and one study in the domain of eco labels [39] that found that interpretative labels are more effective than reductive labels, we hypothesized that 
interpretative labels would lead to more sustainable choices compared to the reductive labels, as well as compared to no labels.

\section{Study 1}

This first experiment studied the impact of an interpretative eco label and an interpretative nutrition label on the sustainability of food choices in an online decision task.

\subsection{Materials and Methods}

\subsubsection{Design and Procedure}

The experiment consisted of a between-subjects design in which participants were randomly allocated to one of three conditions (i.e., eco-themed label, nutrition-themed label, no label). The research protocol was reviewed and approved by the university's ethical committee.

The experiment was set up in Qualtrics, and included a choice task with an online web shop design (see Figure A1 in Appendix A). Participants received the following instructions: 'We would like you to imagine that you are shopping online for ingredients to make a pasta dish for yourself (1 person). You can compose this meal as you like. You can add any ingredient to your shopping list, and you can select as many ingredients as you like'. A pasta dish was chosen given the many possible varieties. The shop included 30 food products from four categories, i.e., proteins (e.g., meat, fish, vegetarian meat), vegetables, pasta, and sauce. The category order was randomized between participants. We consulted the website of a famous Flemish chef (i.e., Jeroen Meus) who is known for making 'everyday food', and included the products from several pasta recipes. Following a meeting with members of the research team, additional products were included (e.g., plant-based protein products) to allow more variation in terms of healthiness and sustainability. Participants were able to make different types of dishes with the available products. The products were presented without packaging. Each product was presented with a product name, a product picture, a reference quantity, and with or without a label. After choosing their ingredients, participants received an overview and indicated the quantities they would use (in grams) to make the meal for themselves. To facilitate this, the weight of one serving of that product (e.g., the weight of one medium-sized mushroom, one regular-sized bowl of tomato juice) was provided. By instructing participants to imagine that they were making the meal just for themselves, we tried to reduce the influence of social norms commonly associated with ecological food decision-making [44]. Although young adults generally have positive attitudes towards sustainability, they do not always perceive support from their friends or families to buy sustainable products [12]. Moreover, by asking participants to indicate the desired quantities for a one-person meal, the outcome of this experiment more closely resembles serving choices. The study therefore differs from previous studies in the same domain that only investigated product choices [24,39,41,42].

Depending on the condition, the products were presented either with a nutritionthemed label, an eco-themed label, or without a label. The nutrition label was the nutriscore label, which is well-known in Flanders where the experiment took place [45]. This label evaluated the overall nutritional score of the products with a letter from $\mathrm{A}$ to $\mathrm{E}$, and a color from green to red. The products in our experiment received the same scores as on the Belgian 'Delhaize' website [46]. Delhaize is a popular supermarket chain in Belgium, which has implemented the nutri-score on (nearly) all products. The eco label displayed the same score, but this was now presented as the overall 'eco-score' of that product (see Figure 1). To our knowledge, there is currently no easy method available to calculate a simple summary sustainability score of different food products. Although it is theoretically possible to calculate the Life Cycle Assessment of food products (LCA; i.e., the overall environmental impact of a product taking all different production and consumption stages into account), this method is complex and considered outside the scope of the current research. In addition, the LCA cannot be transformed to a letter score and does not allow an easy comparison between products [47]. We therefore decided to present the products' 
nutri-scores as their eco-scores in the eco label condition. We realize that the eco labels are therefore not a completely accurate reflection of the products' environmental impact. However, this method was based on the fact that healthy food products are often also sustainable [3]. Moreover, the decision to create a fictional ecological equivalent was also based on the fact that most Flemish consumers' are acquainted with the nutri-score label and understand its meaning [45]. When confronted with new labels, it usually takes some time and effort to develop understanding. However, prior experience can facilitate the adoption process [48], which is why we chose a familiar label.

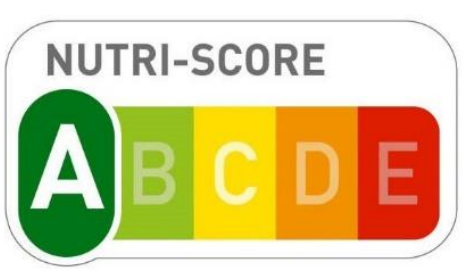

(a)

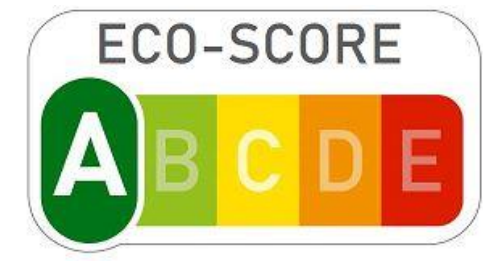

(b)

Figure 1. Label stimuli used in Study 1. (a) Nutrition label and (b) Eco label.

\subsubsection{Participants}

A convenience sample of young adults took part in the study. Young adults are in an important life stage in which they start to make more independent decisions such as which foods to buy, cook, and eat [49]. Unfortunately, this age group is at risk of making poor dietary decisions. Despite an interest in making healthy and sustainable eating choices, young adults feel inhibited to do so by factors in their physical and social environment [49]. Therefore, they are an important group to target with cues such as labels.

Participants were undergraduate students at a Flemish university. For one of their courses, the students were required to complete a weekly online assignment (unrelated to the study). At the end of one of these assignments, there was a written invitation to participate in an online study about food. They were informed that participation was voluntary and that their answers would remain anonymous. 182 students completed the assignment and received the invitation, of which 156 (response rate $=85.7 \%$ ) completed the study.

Data-cleaning was carried out on this group of participants. We used boxplots to detect outlier scores on three outcome variables, i.e., the meat quantity, the carbon footprint and the blue water footprint of the composed meals. 18 participants scored at least 3 standard deviations from the mean for at least one of these variables. We checked the products and quantities that these participants had selected. We excluded 14 participants who provided highly unrealistic quantities for a one-person meal, suggesting random answering. After cleaning, 142 participants $(83.0 \%$ female, $M=20.64, S D=1.59)$ were included in the data-analyses. The participants had a mean self-reported BMI of 22.11 $(S D=3.23)$, and about $15 \%$ were overweight $(n=22 ; B M I>25)$.

\subsubsection{Measures}

Label compliance score. We assigned a score to each food product corresponding with the letter score displayed alongside the product (i.e., A-score $=1$, B-score $=2$, C-score $=3$, D-score $=4$, E-score $=5$ ). We calculated a total score based on participants' chosen ingredients, along the same lines as Poquet et al. (2019). This score increased as participants included more ingredients, especially if they were presented with 'inferior' product scores. Therefore, a lower score should reflect a higher compliance with the information presented in the labels.

Meal outcomes are the other main outcomes related to the sustainability of participants' food choices. The Food and Agricultural Organization of the UN defines sustainable diets as "diets with low environmental impacts which contribute to food and nutrition security, and to healthy life for present and future generations" [50]. The release of greenhouse gas 
emissions and freshwater use are ranked among the main environmental impacts of food production [1,51]. Therefore, we decided to focus on these environmental impact measures, and to calculate the total carbon footprint (in grams) and the total blue water footprint (in liters) of the meals that participants had composed. The Dutch 'National Institute for Health and Environment' (RIVM) defines the carbon footprint as "all greenhouse gas emissions released during the life cycle of the product", and the blue water footprint as "all fresh water use during the cultivation of crops". We calculated these two footprint values for the entire meal, based on the environmental impact values per $100 \mathrm{~g}$ of food products provided by the RIVM [51]. These values were not available for five products in our experiment (i.e., celery, asparagus, eggplant, leek, and pesto sauce). Therefore, we calculated mean carbon and blue water footprints for these five products based on the footprints of the other products in that category. In addition, we also calculated the total meat quantity (in grams) included in the participant's meal. We also calculated four nutritional values, namely the amount of energy (in calories), fats (in grams), proteins (in grams), and sugars (in grams). Table S1 in the Supplementary Material provides an overview of the environmental and nutritional values per $100 \mathrm{~g}$ of the food products included in the experiment. It should be noted that this table only includes four nutritional values. It might, therefore, give a slightly different impression of the products' overall nutritional value than the nutri-score, which takes additional values into account.

Survey questions. After the online choice task, participants answered a set of questions. The first set of questions related to participants' attitudes towards health and sustainability, as well as personal values. We included these variables as covariates in the analyses, given that previous research has found them to be associated with pro-environmental food purchases [15]. Participants indicated their general health concern with five items [52]. An example item is 'Living life in the best possible health is very important to me', which was answered on a 5-point Likert-scale (ranging from 'completely disagree' to 'completely agree'). Participants' general environmental concern was measured with a short version of the new ecological paradigm scale [53]. The scale included seven items such as 'The human being seriously abuses the environment' and was answered on a 7-point scale (completely disagree - completely agree). Subsequently, participants' social value orientation was measured, a concept which reflects how people relate to themselves and to others. Specifically, they indicated how important they find twelve fundamental concepts related to egoistic (e.g., authority), altruistic (e.g., equality) and biospheric (e.g., unity with nature) values on a 9-point scale (ranging from 'I oppose that principle' to 'very important') [54].

Participants also answered questions about their past food consumption behaviors, as well as perceived social norms, situational hunger, and socio-demographic variables. We included these variables as covariates, given that they have been associated with proenvironmental food purchases [17] and food label use [55,56]. To get an indication of possible vegetarian eating patterns, participants were asked 'how many days during the past week they had eaten vegetarian (no consumption of meats or fish)' on a scale from 'no single day' to 'every day'. Participants answered the same question with respect to pescatarian eating (no consumption of meats). They also indicated how many people they usually cook for. Peer descriptive norms were measured with one item; participants indicated how much organic food they think that they eat compared to their peers on a 7-point scale (much less organic foods-much more organic foods). Participants also indicated how hungry they were during the choice task on a 4-point scale (not at all hungry-very hungry) [57]. Finally, we measured demographic variables, specifically age, gender, height, and weight. The latter two measures were used to calculate participants (self-reported) BMI. 


\subsubsection{Statistical Analyses}

Analyses were carried out in SPSS 26. To investigate whether the labels influenced participants' product choices and meal outcomes, we conducted a MANOVA (without covariates) with the label conditions as the independent variable and the label compliance score, the meat quantity, the carbon footprint and the blue water footprint of the meal as dependent variables. We investigated whether the assumptions for MANOVA were met prior to conducting the analysis. We then conducted the same analysis including the abovementioned covariates. Finally, we conducted similar analyses with the nutritional values (e.g., energy, fats, proteins and sugars) of the meals as dependent variables. The results of these analyses can be consulted in document S2 in the Supplementary Material.

\subsection{Results}

Table 1 provides an overview of the participants' sociodemographic and lifestyle factors. With regard to their past food consumption, about $24 \%$ of the participants had eaten meat every single day during the week before the experiment. More than $13 \%$ had eaten vegetarian (no meat, no fish) every day, while 3\% had eaten pescatarian (no meat) every day. Participants indicated that they usually cooked for only one or two people.

Table 1. Participants' sociodemographic and lifestyle factors.

\begin{tabular}{ccc}
\hline Factor & M & SD \\
\hline Age & 20.64 & 1.59 \\
BMI & 22.11 & 3.23 \\
Health concern (5-point scale) & 3.64 & 0.57 \\
Environmental concern (7-point scale) & 4.19 & 0.41 \\
Egoistic values (9-point scale) & 5.19 & 1.14 \\
Altruistic values (9-point scale) & 7.92 & 0.96 \\
Biospheric values (9-point scale) & 7.39 & 1.19 \\
Peer descriptive norm (7-point scale) & 4.48 & 1.44 \\
Hunger (4-point scale) & 1.58 & 0.78 \\
\hline
\end{tabular}

The MANOVA met all the assumptions (e.g., homogeneity of covariance matrices, collinearity between dependent variables, etc.), except the assumption of normal distribution. Specifically, Kolmogorov-Smirnov tests showed that the label compliance score $(D(142)=0.187, p<.000)$, the meat quantity $(D(142)=0.30, p<0.000)$, the carbon footprint $(D(142)=0.12, p<0.000)$, and the blue water footprint $(D(142)=0.08, p=0.015)$ were all (somewhat) skewed to the right. The MANOVA (without covariates) revealed no significant impact of the labels on the compliance score $\left(F(2,139)=0.406, p=0.667, \eta_{p}{ }^{2}=0.006\right)$, nor on the meat quantity $\left(F(2,139)=0.463, p=0.63, \eta_{p}{ }^{2}=0.007\right)$, the carbon footprint $\left(F(2,139)=0.929, p=0.40, \eta_{p}^{2}=0.013\right)$ or the blue water footprint $(F(2,139)=1.37, p=0.26$, $\left.\eta_{p}{ }^{2}=0.019\right)$ of the meals. Table 2 provides an overview of the compliance scores and environmental values (with means and standard deviations) across the label groups. More specifically, contrary to our expectations, participants who saw the eco-themed labels did not compose a meal with less meat compared to participants who saw no labels $(p=0.37)$ or participants who saw the nutrition-themed labels $(p=0.88)$. The eco-themed labels also did not lead them to compose a meal with a lower carbon or blue water footprint compared to no labels (carbon: $p=0.23$, blue water: $p=0.37$ ) or compared to the nutrition-themed labels (carbon: $p=0.95$; blue water: $p=0.45$ ). When the outlier scores were included in the analysis, the results remained the same. 
Table 2. Compliance scores and environmental values across label groups

\begin{tabular}{ccccc}
\hline \multirow{2}{*}{ Outcome } & Label & $\mathbf{M}$ & SD & N \\
\hline \multirow{4}{*}{ Label compliance score } & Interpretative eco label & 10.61 & 4.25 & 47 \\
\cline { 2 - 4 } & Interpretative nutrition label & 10.20 & 3.68 & 48 \\
\cline { 2 - 4 } & No label (control) & 9.89 & 3.75 & 47 \\
\hline \multirow{2}{*}{$\begin{array}{c}\text { Meat quantity } \\
\text { (in grams) }\end{array}$} & Interpretative eco label & 78.29 & 84.63 & 47 \\
\cline { 2 - 4 } & Interpretative nutrition label & 80.93 & 87.69 & 48 \\
\cline { 2 - 4 } Carbon footprint & No Label (control) & 65.11 & 84.80 & 47 \\
\cline { 2 - 4 } (in grams) & Interpretative eco label & 3764.63 & 2065.30 & 47 \\
\cline { 2 - 4 } & Interpretative nutrition label & 3791.85 & 2096.97 & 48 \\
\cline { 2 - 4 } Blue water footprint & No Label (control) & 3266.39 & 2160.72 & 47 \\
\hline (in liters) & Interpretative eco label & 114.13 & 54.60 & 47 \\
& Interpretative nutrition label & 106.23 & 47.22 & 48 \\
\hline & No Label (control) & 96.81 & 50.17 & 47 \\
\hline
\end{tabular}

The same analysis with covariates showed that participants' hunger was significantly associated with the different meal outcomes, i.e., the meat quantity $(F(1,124)=9.50$, $\left.p=0.003, \eta_{p}^{2}=0.071\right)$, the carbon footprint $\left(F(1,124)=11.89, p=0.001, \eta_{p}^{2}=0.087\right)$, and the blue water footprint $\left(F(1,124)=4.69, p=0.032, \eta_{p}{ }^{2}=0.036\right)$. A higher level of hunger during the experiment was associated with less sustainable choices. Past vegetarian consumption was also significantly associated with the meat quantity $(F(1,124)=14.77, p=0.0001$, $\left.\eta_{p}{ }^{2}=0.106\right)$, and the carbon footprint $\left(F(1,124)=4.51, p=0.036, \eta_{p}^{2}=0.035\right)$ of the meals. Specifically, a higher number of days of vegetarian eating before the experiment was associated with more sustainable choices during the experiment. The other covariates were not significantly associated with the three environmental value outcomes ( $p^{\prime}$ s $\left.>0.05\right)$. When all covariates were included, similar results were found with regard to the impact of the labels.

\subsection{Discussion}

The findings of the first experiment revealed no evidence that young adults make more sustainable choices when labels are presented with a sustainability theme, compared to no labels or compared to nutrition-themed labels. We also found no evidence that these labels influenced young adults to limit their choices of 'inferior' products. The results even seem to point to more sustainable choices being made in the (control) setting where no labels were present. One reason for this non-finding with regard to the sustainability outcomes may be that the eco-themed labels displayed the nutritional score of the products, which only resembles their actual environmental scores. Therefore, the labels were only roughly able to point participants towards the (most) sustainable options. However, the experiment included two fish products (i.e., salmon and cod), which are considered healthy, but less sustainable. Nevertheless, they received an A-score for both healthiness and sustainability. In that particular case, the eco-themed label could have falsely guided participants towards less sustainable choices. For most of the food products included in our experiments, however, there is a considerable overlap between the nutritional and sustainability values. This is also demonstrated in the results of our experiments; we found moderate to high correlations between the environmental values and the nutritional values of the composed meals (Mean $r=0.446$ ). Given that these values were objectively measured based on participants' product choices, they indicate an adequate similarity between the healthiness and the sustainability of the food choices made by participants. Table 1 in document S3 provides the correlations between all variables included in the study. Another reason for the non-finding may be a lack of power. Previous research found a medium-sized effect $(d=0.57)$ of a similar eco label format on the environmental impact of food choices compared to a no label control [39]. With 95 participants (eco label: $n=48$, 
control: $n=47$ ), our study only had $62 \%$ power to detect this difference at the $5 \%$ statistical significance level. Moreover, we found no evidence that the nutri-score label influenced the sustainability of the meals. We also found no evidence that this label influenced nutritional values, contrary to the findings of Poquet et al. (2019).

Regardless of the labels, participants made quite sustainable choices in the online decision task. For instance, more than one third (i.e., 36.6\%) of the participants composed a meal without meat. This relatively low choice for meat could be explained by the participants' past vegetarian consumption behaviors. Specifically, about $13 \%$ of the participants reported that they had eaten vegetarian (no meat, no fish) every single day during the week before the experiment. This is much higher than the share of vegetarians in Flanders (i.e., $3 \%$ ), and even higher than the share of people who eat a vegetarian meal at least 3 times a week (i.e., 8\%) [58].

These findings could be the result of a self-selection bias in our sample. Participants were all undergraduate students, and mostly female (i.e., 83\%). A higher educational level and being female are both associated with a higher level of nutrition knowledge [59]. Previous studies have suggested that subjective nutrition knowledge influences people's response to labels, such that people with low self-perceived nutrition knowledge prefer and respond more favorably to simple labels, whereas people with high self-perceived nutrition knowledge prefer more detailed labels [60-62]. This effect of knowledge may explain why our sample did not respond to the simple nutri-score and eco-score labels. Therefore, a follow-up experiment is needed, in which labels with different levels of complexity are introduced, and in which participants' knowledge is taken into account.

\section{Study 2}

Building on study 1, we further wanted to evaluate whether labels could influence a shift towards more sustainable food choices. The second study included two different versions of the eco and nutrition labels, varying in complexity (see Table 1). Similar to the first study, there was an interpretative (i.e., simple, evaluative) version. We also introduced a reductive (i.e., detailed, factual) version. We studied the impact of the labels' theme and complexity, as well as the potential role of participants' nutritional and environmental knowledge.

\subsection{Materials and Methods}

\subsubsection{Design and Procedure}

An experiment with a 2 (label theme: sustainability vs. nutrition) $\times 2$ (label complexity: interpretative vs. reductive) plus 1 control group (no label) between-subjects design was conducted. Participants were randomly assigned to one of the five groups.

The procedure was similar to the one used in study 1, with some small differences (see Figure A2 in Appendix B). First, we varied the products that participants could choose from. For instance, some additional meat products were added to the protein category, and fish products were no longer included. We also added a fifth category (i.e., cheese). The presentation of the products was similar to study 1, except that the products were now presented with packaging and price to create a more realistic decision experience. Moreover, according to a recent review, food packaging cues can play an important role in guiding food choices [25].

The products were displayed with or without a label. Table 3 provides an overview of the stimuli. Similar to the first study, there was an interpretative version of the eco label (i.e., the 'eco-score' label) and the nutrition label (i.e., the 'nutri-score' label). In addition to the procedure used in study 1, there was a reductive (i.e., detailed, factual) version, which resembled the existing 'Guidelines Daily Amount' nutrition label format. The reductive eco label displayed four sustainability values, i.e., the water use (in liters), the carbon footprint (in grams), the land use (in $\mathrm{m}^{2} /$ year), and the nitrogen (in grams) per 100 grams of a food product. These four values were calculated for each individual product based on the data provided by the RIVM [51], and should accurately reflect the 
products' environmental impact value. The reductive version of the nutrition label similarly presented four nutritional values, i.e., the energy (in calories) and the amount of saturated fats (in grams), sugar (in grams), and salt (in grams) per $100 \mathrm{~g}$ of that product. Given that we used existing, packaged products, we used the actual nutritional values mentioned in the nutritional table of the product. Finally, there was a control condition in which the products were displayed without labels.

Table 3. Label stimuli used in study 2.

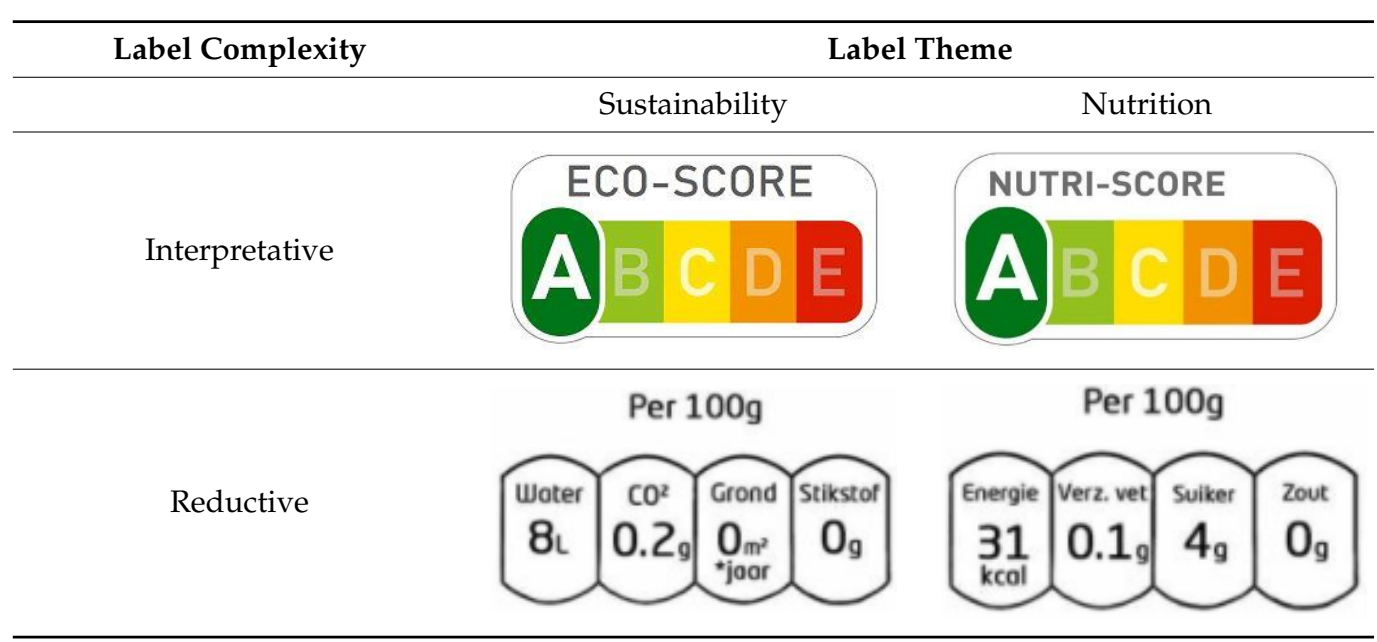

\subsubsection{Participants}

Young adults were invited to participate via posts on a master student's social media accounts. The posts mentioned that young adults could participate voluntarily in an online study about food. A total of 264 participants took part in the experiment. The sample size was opportunistic. We used the same data-cleaning methods as in the first study. 14 participants were excluded because they had provided quantities that were highly unlikely for a one-person meal. After cleaning, the sample was brought down to 250 participants. The average age was 21.81 years $(S D=1.54)$, and the sample was predominantly female (i.e., $81.6 \%$ ), similar to Study 1. Participants were highly-educated, with the majority of the sample (i.e., 86.8\%) having or pursuing a degree in higher education.

\subsubsection{Measures}

Label compliance score. The calculation of this score was similar to Study 1.

Meal outcomes. The environmental impact values, i.e., the meat quantity (in grams), the carbon footprint (in grams), and the blue water footprint (in liters) were calculated in the same way as in study 1. For six products in our experiment (i.e., red pesto sauce, green pesto sauce, 5 formaggi sauce, carbonara sauce, parmesan cheese, and feta cheese), the environmental impact values per $100 \mathrm{~g}$ were not available [51]. Similar to study 1 , we calculated the average carbon and blue water footprint based on the footprints of the other products in that category. Finally, the nutritional values, i.e., the energy (in calories), fats (in grams), proteins (in grams), and sugar (in grams) were calculated in the same way as in study 1. Table S4 in the Supplementary Material provides an overview of the environmental and nutritional values per $100 \mathrm{~g}$ of the food products included in the experiment.

Survey questions. Participants' health concern and environmental concern were measured in the same way as in study 1 . Additionally, we adapted the subjective knowledge scale by Flynn and Goldsmith (1999) to measure participants' subjective knowledge about nutrition and sustainability. They indicated to what extent they agreed with nine items, for instance "I know pretty much about healthy food/sustainable food" and "I know how to judge the quality of healthy food/sustainable food", on a 7-point scale (ranging from 'completely disagree' to 'completely agree'). Similar to Study 1, concerns about health and 
sustainability were included as covariates in the data-analyses. We also controlled for the subjective knowledge about nutrition and sustainability measures.

To get an idea of past consumption behaviors, we asked how often during the past week they had eaten a meal including meat (not once-multiple times per day). They also indicated how they would identify themselves with respect to meat consumption, and could choose between different categories (e.g., meat-eater, vegetarian, flexitarian). In an open question, they could also indicate food allergies. Similar to study 1 , they answered how many people they usually cook for, and how hungry they were during the experiment. Lastly, demographic variables such as age and gender were measured. Similar to Study 1, all these variables were included as covariates in the data-analyses.

\subsubsection{Statistical Analyses}

Similar to study 1, we conducted a MANOVA (without covariates) with the interpretative label conditions (eco-score vs. nutri-score vs. control) as the independent variable and the label compliance score, the meat quantity, the carbon footprint, and the blue water footprint as the dependent variables. In addition, we also conducted a 2 (label theme: sustainability vs. nutrition) $\times 2$ (label complexity: interpretative vs. reductive) MANOVA (without covariates) with the meat quantity, the carbon footprint, and the blue water footprint as the dependent variables. We then conducted separate analyses to compare the experimental conditions with the control condition. Significant differences were followed up using LSD post hoc tests. We investigated whether the assumptions for MANOVA were met prior to the analyses. We later controlled for the abovementioned survey variables. We conducted the same analyses with the four nutritional values (i.e., energy, fat, sugar and protein) as the dependent variables. The results of these analyses can be consulted in document S2 in the Supplementary Material.

In addition, we included participants' level of hunger in the MANOVA as a potential moderator of the impact of the labels' theme or complexity. We also investigated whether young adults' nutrition or sustainability knowledge played a moderating role in the impact of the labels' complexity (i.e., interpretative vs. reductive vs. control) on the three environmental values.

\subsection{Results}

Table 4 provides an overview of the participants' sociodemographic and lifestyle factors. The majority of the participants (i.e., $64.4 \%$ ) identified as meat-eaters. The remaining participants followed an alternative diet (i.e., $23.6 \%$ flexitarian, $7.6 \%$ vegetarian, $1.2 \%$ pescatarian, and $0.8 \%$ vegan). About $47 \%$ of the participants had eaten meat nearly every day during the week before the experiment, while about $10 \%$ had not eaten any meat that week. Most of the participants (i.e., 98\%) indicated that they cooked at least sometimes, and that they mostly cooked for one or two people.

Table 4. Participants' sociodemographic and lifestyle factors.

\begin{tabular}{ccc}
\hline Factor & M & SD \\
\hline Age & 21.81 & 1.54 \\
Health concern (5-point scale) & 3.63 & 0.54 \\
Environmental concern (7-point scale) & 5.30 & 0.79 \\
Subjective nutrition knowledge (7-point scale) & 4.41 & 1.05 \\
Subjective environmental knowledge (7-point scale) & 3.38 & 1.06 \\
Hunger (4-point scale) & 2.08 & 1.17 \\
\hline
\end{tabular}

The MANOVA met all the assumptions, except the assumption of normal distribution. Specifically, Kolmogorov-Smirnov tests revealed that the label compliance score $(D(250)=0.10, p<0.000)$, the meat quantity $(D(250)=0.15, p<0.000)$, the carbon footprint $(D(250)=0.12, p<0.000)$, and the blue water footprint $(D(250)=0.09, p<0.000)$ did not follow a normal distribution, but were all (somewhat) skewed to the right. The first MANOVA 
with the interpretative labels (eco-score vs. nutri-score vs. control) as independent variables revealed no significant impact of these labels on the compliance score $(F(2,152)=0.32$, $\left.p=0.72, \eta_{p}{ }^{2}=0.004\right)$, nor on the meat quantity $\left(F(2,152)=1.40, p=0.25, \eta_{p}{ }^{2}=0.018\right)$, the carbon footprint $\left(F(2,152)=2.25, p=0.11, \eta_{p}^{2}=0.029\right)$, or the blue water footprint $(F(2,152)$ $=1.99, p=0.14, \eta_{p}{ }^{2}=0.026$ ) of the meals. However, a post-hoc analysis with LSD did reveal a significant difference between the eco-score label and the no label control group with regard to the carbon footprint $(p=0.039)$ and a near-significant difference with regard to the blue water footprint $(p=0.051)$. Similar results were found when the covariates were included in the analysis. Table 5 displays an overview of the product and meal outcomes across the interpretative label conditions.

Table 5. Compliance scores and environmental values across interpretative label groups.

\begin{tabular}{ccccc}
\hline Outcome & Label & $\mathbf{M}$ & SD & N \\
\hline \multirow{4}{*}{ Label compliance score } & Interpretative eco label & 14.02 & 5.43 & 46 \\
\cline { 2 - 4 } & Interpretative nutrition label & 13.47 & 4.43 & 53 \\
\cline { 2 - 4 } & No label (control) & 14.19 & 4.83 & 56 \\
\hline \multirow{2}{*}{$\begin{array}{c}\text { Meat quantity } \\
\text { (in grams) }\end{array}$} & Interpretative eco label & 99.89 & 98.16 & 46 \\
\cline { 2 - 4 } & Interpretative nutrition label & 121.04 & 101.98 & 53 \\
\cline { 2 - 4 } $\begin{array}{c}\text { Carbon footprint } \\
\text { (in grams) }\end{array}$ & No label (control) & 132.05 & 91.78 & 56 \\
\cline { 2 - 4 } & Interpretative eco label & 3767.88 & 2342.41 & 46 \\
\cline { 2 - 4 } & Interpretative nutrition label & 4459.54 & 2290.30 & 53 \\
\hline \multirow{3}{*}{$\begin{array}{c}\text { Blue water footprint } \\
\text { (in liters) }\end{array}$} & No label (control) & 4745.98 & 2426.59 & 56 \\
\cline { 2 - 4 } & Interpretative eco label & 93.24 & 35.67 & 46 \\
\cline { 2 - 4 } & Interpretative nutrition label & 103.86 & 36.00 & 53 \\
\hline
\end{tabular}

Furthermore, the $2 \times 2$ MANOVA revealed that the label theme (sustainability vs. nutrition) significantly influenced the meat quantity $\left(F(1,190)=4.55, p=0.034, \eta_{p}{ }^{2}=0.023\right)$, the carbon footprint $\left(F(1,190)=5.36, p=0.022, \eta_{p}^{2}=0.027\right)$, and the blue water footprint $\left(F(1,190)=7.26, p=0.008, \eta_{p}{ }^{2}=0.037\right)$ of the meals. When covariates were included in the analysis, the results remained the same. Table 6 displays an overview of the environmental values across label themes. Specifically, compared to the nutrition-themed labels, the ecothemed labels influenced participants to compose a meal with less meat, and with a lower carbon and blue water footprint. When compared to the control group, the eco-themed labels had a significant impact on the meat quantity $(p=0.038)$, but not on the carbon footprint $(p=0.065)$ or the blue water footprint $(p=0.088)$. There were no significant differences between the nutrition-themed labels and the control group for all three outcome variables $\left(p^{\prime}\right.$ s $\left.>0.05\right)$. In addition, we investigated whether the significant impact of the label theme persisted when the outlier scores were included in the analysis. The $2 \times 2$ MANOVA with outlier scores $(\mathrm{n}=264)$ indicated that this was not the case, and that the label theme no longer had a significant impact on the meat quantity $\left(F(1,204)=1.82, p=0.18, \eta_{p}^{2}=0.009\right)$, the carbon footprint $\left(F(1,204)=2.40, p=0.12, \eta_{p}{ }^{2}=0.012\right)$ or the blue water footprint $\left(F(1,204)=3.15, p=0.07, \eta_{p}^{2}=0.015\right)$. 
Table 6. Environmental values across label theme groups.

\begin{tabular}{ccccc}
\hline Outcome & Label Theme & M & SD & N \\
\hline \multirow{3}{*}{ Meat quantity (in grams) } & Sustainability & 97.19 & 95.53 & 98 \\
\cline { 2 - 4 } & Nutrition & 127.91 & 107.52 & 96 \\
\cline { 2 - 4 } & No label (control) & 132.05 & 91.78 & 56 \\
\hline \multirow{3}{*}{\begin{tabular}{c} 
Carbon footprint (in grams) \\
\cline { 2 - 4 }
\end{tabular}} & Sustainability & 3968.60 & 2474.59 & 98 \\
\cline { 2 - 4 } & Nutrition & 4763.11 & 2572.23 & 96 \\
\hline \multirow{2}{*}{$\begin{array}{c}\text { Blue water footprint } \\
\text { (in liters) }\end{array}$} & No label (control) & 4745.98 & 2426.59 & 56 \\
\cline { 2 - 4 } & Sustainability & 96.55 & 39.88 & 98 \\
\cline { 2 - 4 } & Nutrition & 111.30 & 42.06 & 96 \\
\hline
\end{tabular}

The results of the $2 \times 2$ MANOVA also revealed no significant impact of the label complexity (interpretative vs. reductive) on the meat quantity $(F(1,190)=0.12, p=0.73$, $\left.\eta_{p}{ }^{2}=0.001\right)$ or the carbon footprint $\left(F(1,190)=2.11, p=0.45, \eta_{p}{ }^{2}=0.011\right)$. It should be noted though that the impact of the label complexity on the blue water footprint approached significance $\left(F(1,190)=3.80, p=0.053, \eta_{p}{ }^{2}=0.020\right)$. When covariates were included in the analysis, the results remained the same. Table 7 displays an overview of the environmental values across label complexities. More specifically, compared to the reductive labels, the interpretative labels seemed to influence participants to compose a meal with a lower blue water footprint. When outliers were included in the analysis, the impact of the label complexity on the blue water footprint moved further away from significance $\left(F(1,204)=3.15, p=0.07, \eta_{p}^{2}=0.015\right)$. No significant differences emerged when comparing both label complexities with the control condition $\left(p^{\prime} \mathrm{s}>0.05\right)$.

Table 7. Environmental values across label complexity groups.

\begin{tabular}{ccccc}
\hline Outcome & Label Complexity & $\mathbf{M}$ & SD & N \\
\hline \multirow{2}{*}{$\begin{array}{c}\text { Meat quantity } \\
\text { (in grams) }\end{array}$} & Interpretative & 111.21 & 100.27 & 99 \\
\cline { 2 - 4 } & Reductive & 113.63 & 105.38 & 95 \\
\cline { 2 - 4 } & No label (control) & 132.05 & 91.78 & 56 \\
\hline \multirow{2}{*}{$\begin{array}{c}\text { Carbon footprint } \\
\text { (in grams) }\end{array}$} & Interpretative & 4138.17 & 2328.74 & 99 \\
\cline { 2 - 4 } & Reductive & 4594.77 & 2751.39 & 95 \\
\hline \multirow{2}{*}{$\begin{array}{c}\text { Blue water footprint } \\
\text { (in liters) }\end{array}$} & No label (control) & 4745.98 & 2426.59 & 56 \\
\cline { 2 - 4 } & Interpretative & 98.92 & 36.06 & 99 \\
\cline { 2 - 4 } & Reductive & 108.98 & 46.18 & 95 \\
\hline
\end{tabular}

Moreover, no significant interactions emerged between the labels' theme and complexity with respect to the meat quantity $\left(F(1,190)=0.483, p=0.49, \eta_{p}{ }^{2}=0.003\right)$, the carbon footprint $\left(F(1,190)=0.170, p=0.68, \eta_{p}{ }^{2}=0.001\right)$, and the blue water footprint $\left(F(1,190)=0.783, p=0.38, \eta_{p}{ }^{2}=0.004\right)$. Similar results emerged when covariates were included in the analysis.

Furthermore, participants' nutrition knowledge did not moderate the impact of the nutrition labels' complexity (interpretative vs. reductive) on the meat quantity $(F(1,92)=289$, $\left.p=0.35, \eta_{p}{ }^{2}=01\right)$, the carbon footprint $\left(F(1,92)=0.12, p=0.72, \eta_{p}{ }^{2}=0.001\right)$, or the blue water footprint $\left(F(1,92)=0.51, p=0.48, \eta_{p}{ }^{2}=0.005\right)$. However, different results emerged when the interpretative nutrition label (i.e., nutri-score) was compared to the control group. In that case, the impact of the nutrition labels' complexity (nutri-score vs. control) on the meat 
quantity was significantly moderated by participants' nutrition knowledge $(F(1,105)=4.38$, $\left.p=0.039, \eta_{p}{ }^{2}=0.04\right)$. Specifically, compared to the control group, the nutri-score label had a near-significant influence on people with high levels of nutrition knowledge $(t=1.79$, $p=0.07)$ to choose less meat, but not on people with moderate $(t=0.65, p=0.51)$ or low levels of nutrition knowledge $(t=-0.94, p=0.34)$.

The analysis also revealed that participants' environmental knowledge did not moderate the impact of the eco labels' complexity (interpretative vs. reductive) on the meat quantity $\left(F(1,94)=0.016, p=0.90, \eta_{p}^{2}=0.0\right)$, the carbon footprint $(F(1,94)=0.018, p=0.89$, $\left.\eta_{p}{ }^{2}=0.0\right)$, or the blue water footprint $\left(F(1,94)=0.023, p=0.88, \eta_{p}^{2}=0.0\right)$. Similarly, no significant interaction effects occurred when the interpretative eco label was compared to the control group ( $\left.p^{\prime} \mathrm{s}>0.05\right)$.

Finally, a MANOVA revealed that the impact of the label theme (sustainability vs. nutrition vs. control) on the carbon footprint was moderated by participants' level of hunger $\left(F(2,244)=3.29, p=0.039, \eta_{p}^{2}=0.026\right)$. More specifically, compared to the control group, the eco-themed labels influenced people who were not hungry $(t=2.88, p=0.004)$, but not people who were moderately $(t=1.81, p=0.07)$ or really hungry $(t=-0.33, p=0.74)$. Compared to the nutrition-themed labels, the eco-themed labels influenced participants who were not hungry $(t=3.02, p=0.003)$ or moderately hungry $(t=2.24, p=0.026)$, but did not influence participants who were really hungry $(t=0.15, p=0.88)$.

\subsection{Discussion}

Contrary to the results of the first experiment, the results of the second experiment suggest that labels with a sustainability theme can potentially influence more sustainable choices. Exposure to these labels influenced participants to choose less meat compared to labels with a nutrition theme or compared to no labels. The eco-themed labels also influenced meals with a lower carbon and blue water footprint compared to the nutritionthemed labels, but not significantly compared to no labels. A post-hoc power analysis revealed that, based on the sample size of the experiment, there was $85 \%$ power to detect the difference between the eco label and the control group found in the study by Vlaeminck et al. (i.e., $d=0.57 ; 2014$ ) at the $5 \%$ statistical significance level. In addition, when focusing more closely on the interpretative labels, we found that meals had a lower carbon (and blue water) footprint when products were displayed with the eco-score label compared to no label. In line with study 1 , we found no evidence that participants complied with the scores presented in these labels. Similar to study 1, we found no evidence that nutrition-themed labels influenced the sustainability or the nutritional values of the meals.

Interestingly, we found no evidence that the labels' complexity (i.e., interpretative vs. reductive) influenced the sustainability of participants' food choices. The eco-themed labels seemed to have an impact regardless of whether they were interpretative or reductive. Finally, young adults' environmental and nutrition knowledge did not play a major role in their response to the labels varying in complexity. The results did indicate, however, that the interpretative nutrition label (i.e., the nutri-score label) had some impact on how much meat was chosen, but only for young adults with high estimations of their own nutrition knowledge.

\section{Study 1 and Study 2: Overview}

Table 8 provides a complete overview of the environmental outcome values across Study 1 and Study 2. 
Table 8. Compliance scores and environmental values across label groups in Study 1 and Study 2.

\begin{tabular}{|c|c|c|c|c|c|c|c|}
\hline & & & Study 1 & & & Study 2 & \\
\hline Outcome & Label Group & $\mathbf{M}$ & SD & $\mathbf{N}$ & M & SD & $\mathbf{N}$ \\
\hline \multirow{5}{*}{ Label compliance score } & Interpretative eco label & 10.61 & 4.25 & 47 & 14.02 & 5.43 & 46 \\
\hline & Interpretative nutrition label & 10.20 & 3.68 & 48 & 13.47 & 4.43 & 53 \\
\hline & Reductive eco label & - & - & - & - & - & - \\
\hline & Reductive nutrition label & - & - & - & - & - & - \\
\hline & No label (control) & 9.89 & 3.75 & 47 & 14.19 & 4.83 & 56 \\
\hline \multirow{5}{*}{$\begin{array}{l}\text { Meat quantity } \\
\text { (in grams) }\end{array}$} & Interpretative eco label & 78.29 & 84.63 & 47 & 99.89 & 98.16 & 46 \\
\hline & Interpretative nutrition label & 80.93 & 87.69 & 48 & 121.03 & 101.98 & 53 \\
\hline & Reductive eco label & - & - & - & 94.80 & 94.04 & 52 \\
\hline & Reductive nutrition label & - & - & - & 136.40 & 114.64 & 43 \\
\hline & No label (control) & 65.11 & 84.80 & 47 & 132.05 & 91.78 & 56 \\
\hline \multirow{5}{*}{$\begin{array}{l}\text { Carbon footprint } \\
\quad \text { (in grams) }\end{array}$} & Interpretative eco label & 3764.63 & 2065.30 & 47 & 3767.88 & 2342.41 & 46 \\
\hline & Interpretative nutrition label & 3791.85 & 2096.97 & 48 & 4459.54 & 2290.30 & 53 \\
\hline & Reductive eco label & - & - & - & 4146.16 & 2595.56 & 52 \\
\hline & Reductive nutrition label & - & - & - & 5137.28 & 2865.59 & 43 \\
\hline & No label (control) & 3266.39 & 2160.72 & 47 & 4745.98 & 2426.59 & 56 \\
\hline \multirow{5}{*}{$\begin{array}{l}\text { Blue water footprint } \\
\text { (in liters) }\end{array}$} & Interpretative eco label & 114.13 & 54.60 & 47 & 93.24 & 35.67 & 46 \\
\hline & Interpretative nutrition label & 106.23 & 47.22 & 48 & 103.86 & 36.00 & 53 \\
\hline & Reductive eco label & - & - & - & 99.48 & 43.39 & 52 \\
\hline & Reductive nutrition label & - & - & - & 120.48 & 47.33 & 43 \\
\hline & No label (control) & 96.81 & 50.17 & 47 & 108.50 & 44.04 & 56 \\
\hline
\end{tabular}

\section{General Discussion}

The main aim of the current research was to investigate the impact of eco label formats on the environmental footprint of online grocery choices. In particular, we wanted to test the impact of an interpretative (i.e., simple, evaluative) eco label with the same format as the so-called 'nutri-score' nutrition label. Previous studies have shown that the nutriscore label, which uses a score and a color to evaluate the overall nutritional value of a food product, helps consumers make out the healthiness of different products [28,29], and improves healthy purchase intentions [28] and choices [63]. Many consumers desire a similar eco label format that allows them to compare the environmental impact of different food products $[11,22]$. However, most of the current eco labels focus on only one environmental attribute (e.g., GHG emissions, farming method, etc.), rather than on the overall environmental impact [11]. Moreover, only two studies have previously tested the impact of an eco label that uses a score to denote the total environmental impact of a product, but those labels were still quite detailed $[39,43]$.

We conducted two experiments to investigate the impact of eco and nutrition label formats on label compliance and on the sustainability of food choices in an online decision task. The experiments provided mixed results. The findings of the first experiment revealed no evidence that simple eco and nutrition labels can influence young adults to choose fewer 'inferior' products, nor that these labels can influence the sustainability of food choices. In contrast, the results of the second experiment suggest that a simple eco-score label can influence more sustainable choices, i.e., with a lower carbon (and blue water) footprint, compared to no labels. In line with study 1 though, we found no evidence that participants complied to the scores in those labels. In addition, the results of the second experiment suggest that labels with a sustainability theme can influence more sustainable 
choices. Specifically, the young adults in our second experiment chose less meat when products were displayed with eco-themed labels, compared to nutrition-themed labels and to no labels. They also composed meals with a lower carbon and blue water footprint compared to the nutrition labels. Similar to the findings of Muller et al. (2019), the findings of our second experiment suggest that eco labels might influence more sustainable food choices, regardless of their level of complexity. It is possible that both eco label formats in our second study succeeded in triggering pro-environmental values and objectives which subsequently primed participants to pay more attention to the sustainability of their choices [21]. Their choices could then be based on the information presented in the labels, but also on their own knowledge and perceptions regarding sustainability. Although the results of our second experiment revealed that young adults composed more sustainable meals in the presence of eco-themed labels, we found no evidence that they complied to the information presented in those labels. This might suggest that the participants in our second experiment were already (somewhat) aware of the environmental impact of different food products, and that they made pro-environmental choices independent of the information presented in the labels. These findings seem to be in line with the idea brought forward in behavioral economics that eco labels can trigger (environmental, personal and social) values, and that environmental information is not the only central element in eco labelling [64]. It should be noted though that, in line with findings from previous studies $[19,22,23]$, the participants in our second experiments estimated their own environmental knowledge to be rather low.

There are a number of possible reasons for the mixed results demonstrated by the two experiments. First of all, although the impact of eco-themed labels was investigated in both experiments, this factor comprised a smaller group of participants in the first experiment where no effect was found. Post-hoc analyses revealed that the first experiment only had $62 \%$ power to detect an effect of eco labels identified in previous research relative to no labels, while the second experiment had $85 \%$ power to detect this effect. Another difference is that participants in the second experiment showed a much higher concern for the global environment, which may point to a higher use of eco-themed labels. Furthermore, different food products were made available in both experiments. For instance, the omission of fish products in the second experiment may have had the consequence that the labels influenced participants to compose a vegetarian meal, while in the first experiment participants could also compose a (less sustainable) pescotarian meal. In addition, the package was presented to participants in the second experiment where an effect was found. This means that several front-of-pack cues such as the brand, product pictures, colors, etc. were also presented, of which we know that they can influence food-related behaviors [25]. Similarly, several previous studies that showed an effect of eco labels also included packaging as part of the stimuli [39,41,42], which was an element missing in our first experiment. Finally, we should be open to the possibility that the effect of eco-themed labels in our second experiment was a false positive. The conclusiveness of our findings is subject to some limitations. For instance, significant effects were followed up with post-hoc analyses that did not correct for multiple comparisons. In addition, it should be noted that the significant effect of the label theme in our second experiment did not persist when outlier scores were included in the analysis.

Interestingly, we found no evidence that the nutri-score label can influence the sustainability and nutritional value of young adults' choices. This non-finding conflicts with previous experimental studies that reported that this nutrition label can influence purchase intentions [28], and improve the nutritional value of food choices [63]. One reason why we found an effect of eco-themed labels but not of nutrition-themed labels might be that consumers seem to favor eco labels over nutritional labels [65].

Moreover, we found no evidence that young adults' environmental or nutrition knowledge played a role in their response to the labels varying in complexity. There was, however, an indication that the nutri-score label marginally influenced young adults with high levels of nutrition knowledge to compose a meal with less meat compared to no labels. 
This finding contrasts with suggestions made in previous research that mainly people with low levels of nutrition knowledge would prefer these simple types of labels [60-62]. One possible reason is that knowledge was measured in subjective terms and that some participants wrongfully estimated their level of nutrition or environmental knowledge. A review in the domain of information literacy has demonstrated a discrepancy between people's actual and self-perceived knowledge and skills [66]. As such, people with high levels of knowledge may severely underestimate their knowledge, and vice versa. This may explain why the participants in our second experiment reported rather low levels of subjective environmental knowledge, despite reporting high levels of environmental concern. However, previous studies that found knowledge to play an important role in people's response to labels also measured subjective knowledge [60-62].

The findings of the second experiment also suggest a hunger bias: the eco-themed labels no longer had an impact when people were (very) hungry during decision-making. This finding may be explained by the fact that hunger induces lower inhibitory control and more impulsive behaviors $[67,68]$. People who are hungry seem to favor short-term pleasures over long-term (especially altruistic) benefits such as sustainability [69]. The findings of our second study are in line with nutritional recommendations that suggest that people should be encouraged to satisfy their hunger feelings before going grocery shopping [70].

Our two experiments provide important contributions to the field. First, they contributed to the few studies that have empirically investigated the impact of eco labels on food choices. Whereas most previous studies have investigated the impact of so-called carbon labels, the current studies included a label that displayed a (so-called) overall ecological score. This study is also among the first, along with the study by Vlaeminck et al. (2014), to take different environmental values into account (i.e., carbon footprint and blue water footprint) to investigate the environmental footprint of participants' choices. Moreover, participants provided the quantities they would use which allowed us to detect more subtle changes in the environmental-friendliness of participants' choices. Third, our experiments add to the findings of Poquet et al. (2019) who investigated whether the nutri-score nutrition label could improve the nutritional value of snack choices. In contrast with this previous study, we found no impact of the nutri-score label on the nutritional value (or on the environmental value) of food choices. Our non-finding raises questions about the effectiveness of this label, calling for further investigations, especially considering recent calls that the nutri-score label should become mandatory in the European Union [30].

We realize that our studies are not without limitations. An important first limitation is the self-selection bias due to the use of non-probability, convenience samples. In both studies, the recruitment message mentioned food, which means that people with an interest in food may have been more likely to take part. Moreover, the sample predominantly consisted of highly-educated (female) young adults who were highly concerned about health and sustainability. Previous studies have demonstrated that gender is associated with food label use, such that women are more likely to use labels than men [55,71]. Therefore, it is unclear whether we would find a (similar) impact of eco-themed labels if males were equally present in the sample. However, we did find similar results when gender was included as a control variable. Second, our studies reflect online grocery choices, but are limited by the fact that participants made hypothetical choices; they did not pay for the products, and did not eat the meal they composed. In addition, our outcome measures should not be generalized to choices made in traditional in-store settings. Previous research has revealed, for instance, that food choices differ in online and offline contexts, such that people generally buy fewer vices online [72]. The food choices made in our experiments may therefore deviate from the in-store choices that young adults typically make. Third, the interpretative eco labels in our experiments did not display completely accurate environmental scores based on LCA assessments. In contrast, the reductive eco-themed label did display completely accurate information about different environmental attributes. This means that the interpretative and reductive labels not only 
differed in complexity, but also in the accuracy of the information that they displayed. However, this mimics the reality of these label formats. Contrary to reductive labels that display very detailed and accurate information, interpretative labels display summarized and simplified information. The accuracy of these labels and their ability to encourage nuanced decision-making can be questioned [73]. However, this is a trade-off to facilitate interpretation and to help consumers make quick decisions. Fourth, we asked participants to estimate the quantities they would use for a one-person meal. Although we provided reference quantities for one serving of a product, this task may have been difficult. This measure is thus prone to error, but we point out that this error was equally present in all conditions. Finally, the experiments investigated an existing label (i.e., the nutri-score label), as well as fictional labels. Unfortunately, we did not measure to what extent participants understood the different labels. However, research suggests that prior experience with labels facilitates the adoption and understanding of a new label [48]. Considering that the fictional labels closely resembled rather well-known existing labels, participants probably had little difficulty adopting and understanding them.

In conclusion, our results point to the potential use of eco-themed labels alongside food products to improve the sustainability of young adults' dietary choices. It should be noted though that these results were not consistently replicated across studies and analyses, and that there are several factors that limit the conclusiveness of our findings. It is possible that eco-themed labels trigger pro-environmental objectives during decision-making and prime young adults' thinking about sustainability. Based on the results of our studies, we cannot provide clear recommendations with regard to the type of information that should be presented on these eco-themed labels. Moreover, our finding concerning hunger bias highlights the value of a message or intervention that influences people to satisfy their hunger feelings before going grocery shopping. Finally, although our two studies do not suggest that (both simple and detailed) nutrition labels are a successful strategy to promote more sustainable and healthier eating choices, this should be taken lightly given the findings from many previous studies that (mainly simple) nutrition labels do influence healthier eating outcomes [25].

In the future, there should be more empirical investigations into the effectiveness of eco labels differing in complexity. These studies should include a more varied sample with more male participants, and participants with varying levels of educational status and environmental concern. These studies should also include labels with accurate environmental information based on LCA assessments. Moreover, future studies should not only focus on the information displayed in eco labels, but they should also consider the role of (personal, social, and environmental) values and objectives triggered by those labels. Furthermore, even though our findings did not reveal that participants' subjective knowledge played a role in their response to the labels, previous studies have shown that this can be the case. Future studies should therefore also investigate to what extent participants actually understand these labels. Moreover, they could include non-hypothetical choices, for instance by asking participants to pay for (a part of) the ingredients. Furthermore, future studies could investigate the impact of providing both nutritional and environmental information alongside food products. It would be interesting to see whether this approach adds to the impact of a single label presence, or whether this causes issues like information overload or dilution effects $[64,74]$. Finally, given that our experiments were among the first to investigate the impact of the nutri-score label on food choices, more empirical research on this topic is warranted.

Supplementary Materials: The following are available online at https:/ /www.mdpi.com/2071-1 050/13/5/2474/s1, Table S1: Overview of the environmental and nutritional values per $100 \mathrm{~g}$ of the food products included in Study 1. Document S2: Additional results of Study 1 and Study 2. Document S3: Correlation matrices of variables included in Study 1 and Study 2. Table S4: Overview of the environmental and nutritional values per $100 \mathrm{~g}$ of the food products included in Study 2. 
Author Contributions: Conceptualization, L.H. and T.S.; methodology, L.H. and T.S.; formal analysis, L.H.; data curation, L.H.; writing-original draft preparation, L.H.; writing-review and editing, Y.Q., F.B. and T.S.; visualization, L.H.; supervision, T.S. All authors have read and agreed to the published version of the manuscript.

Funding: This research received no external funding.

Institutional Review Board Statement: The study was conducted according to the guidelines of the Declaration of Helsinki, and approved by the Ethics Committee of KU Leuven (protocol code: G-2019 11 1843, date of approval: 25/11/19).

Informed Consent Statement: Informed consent was obtained from all subjects involved in the study.

Data Availability Statement: The datasets are openly available, and be consulted via https:/ / osf.io/ wq29a/?view_only=d20c26759176470e8114ccf222e7fa5f.

Acknowledgments: We would like to thank the master student (Katrien Duchène) for her help with the data collection and analysis. We would also like to thank the young adults who took part in our two experiments.

Conflicts of Interest: The authors declare no conflict of interest.

Disclosure of Data Collection and Analysis: All measures, conditions, data exclusions, as well as information regarding the determination of sample sizes have been reported in the manuscript. 


\section{Appendix A}

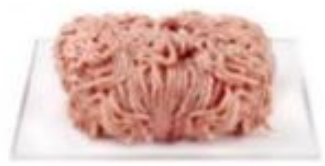

Minced pork

NuTn-scone
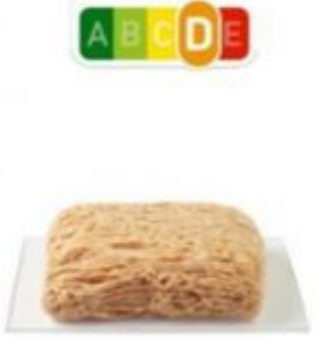

$\square \quad$ Minced chicken
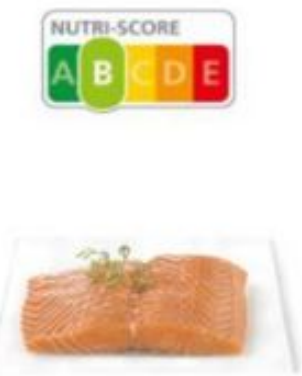

Salmon

\section{A 3 BTRI-SCORE}

1 stuk, de grootte en dikte van een pah

kaarten $=115 \mathrm{~g}$

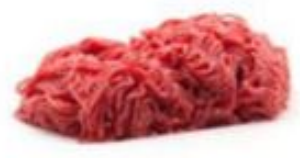

Minced beef

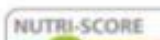

A B C D E

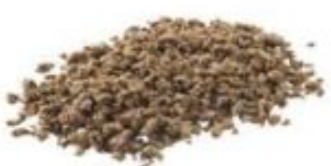

$\square$ Minced vegetarian meat

NUTRL-SCORE

A 3 CD

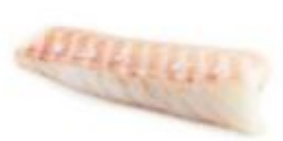

$\operatorname{Cod}$

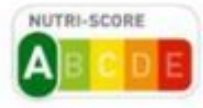

1 stuk, de grootse en diste van een pak karten $=110$ g

Figure A1. Cont. 


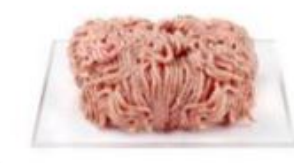

Minced pork

ECO-SCORE
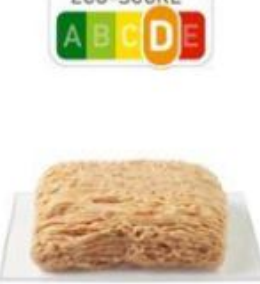

Minced chicken

ECO-SCORE

A B D E

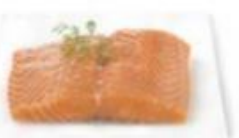

Salmon

ECO-SCORE

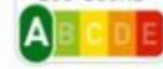

1 stuk, de grootte en dikte van een pak kaarten $=115 \mathrm{~g}$

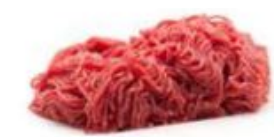

Minced beef

ECO-SCORE

ABCD

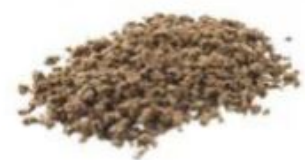

Minced vegetarian meat
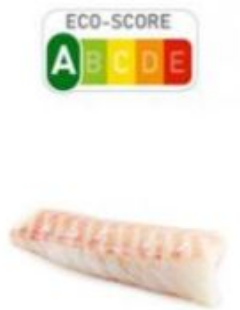

Cod

ECO-SCORE

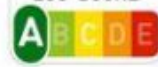

1 stuk, de grootte en dikte van een pak kaarten $=110 \mathrm{~g}$

Figure A1. Cont.
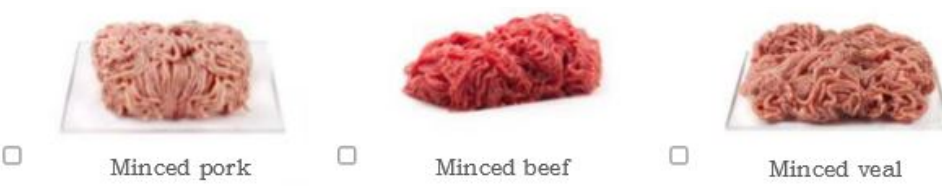

Minced veal

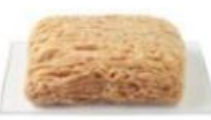

Minced chicken

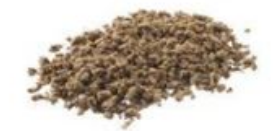

$\square$ Minced vegetarian meat

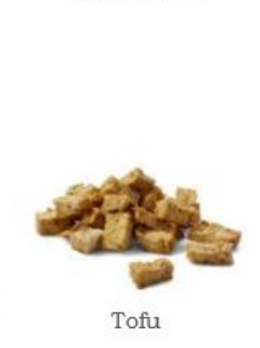

Tofu

ECO-SCORE

A. B 10

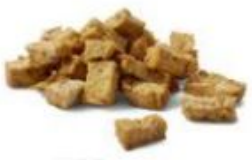

Tofu

ECO-SCORE
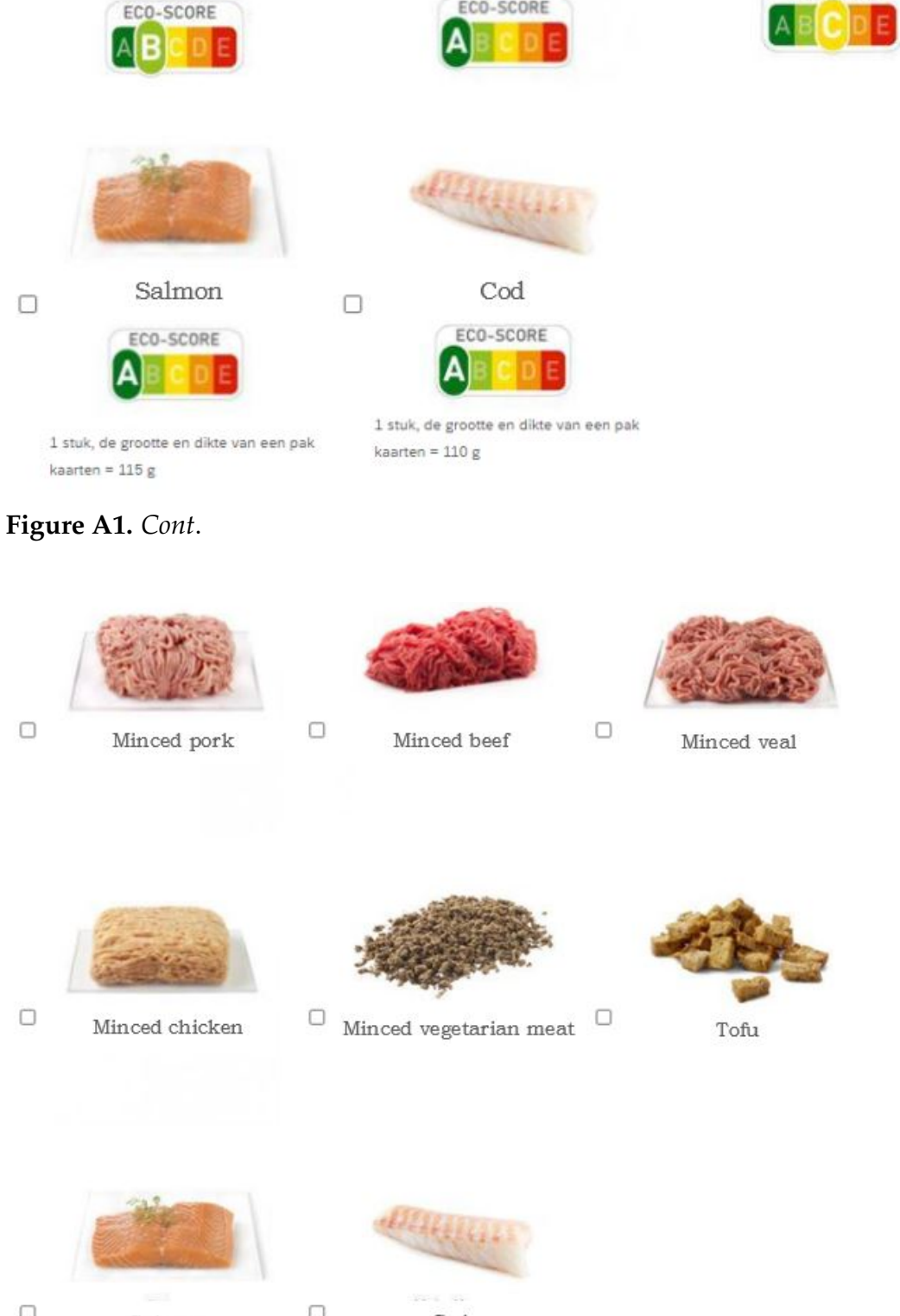

$\square$

Salmon

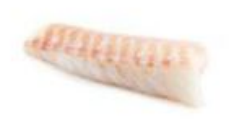

$\square$

Cod

Figure A1. Example of web shop stimuli across different conditions in Study 1. 
Appendix B
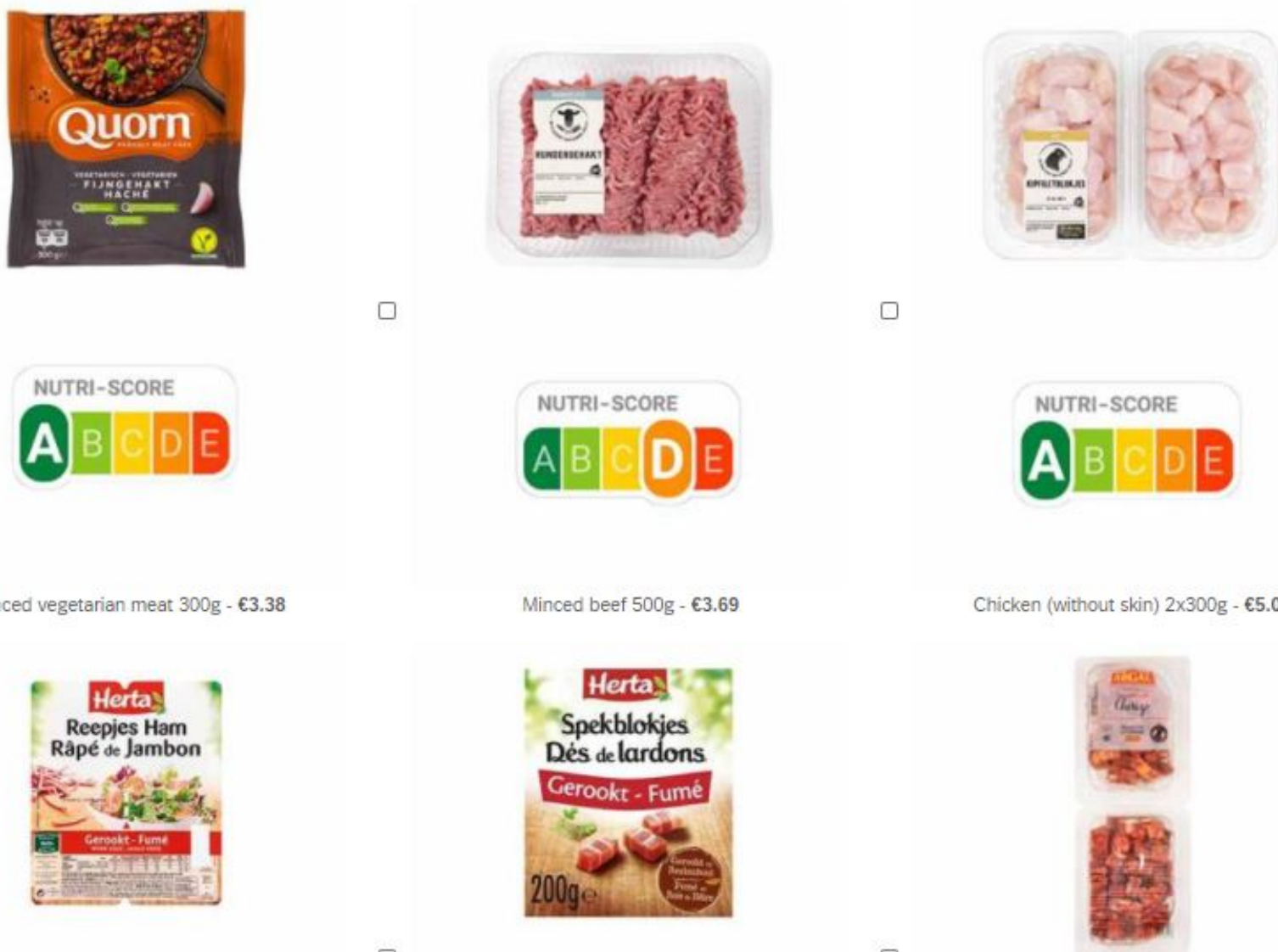

NUTRI-SCORE

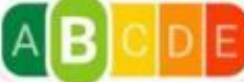

NUTRI-SCORE

NUTRI-SCORE
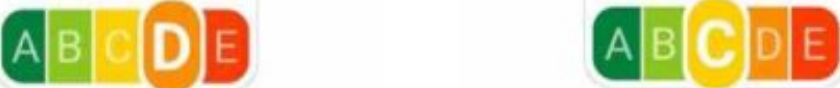

Smoked ham $2 \times 75 g$ - $€ 3.59$

Figure A2. Cont. 

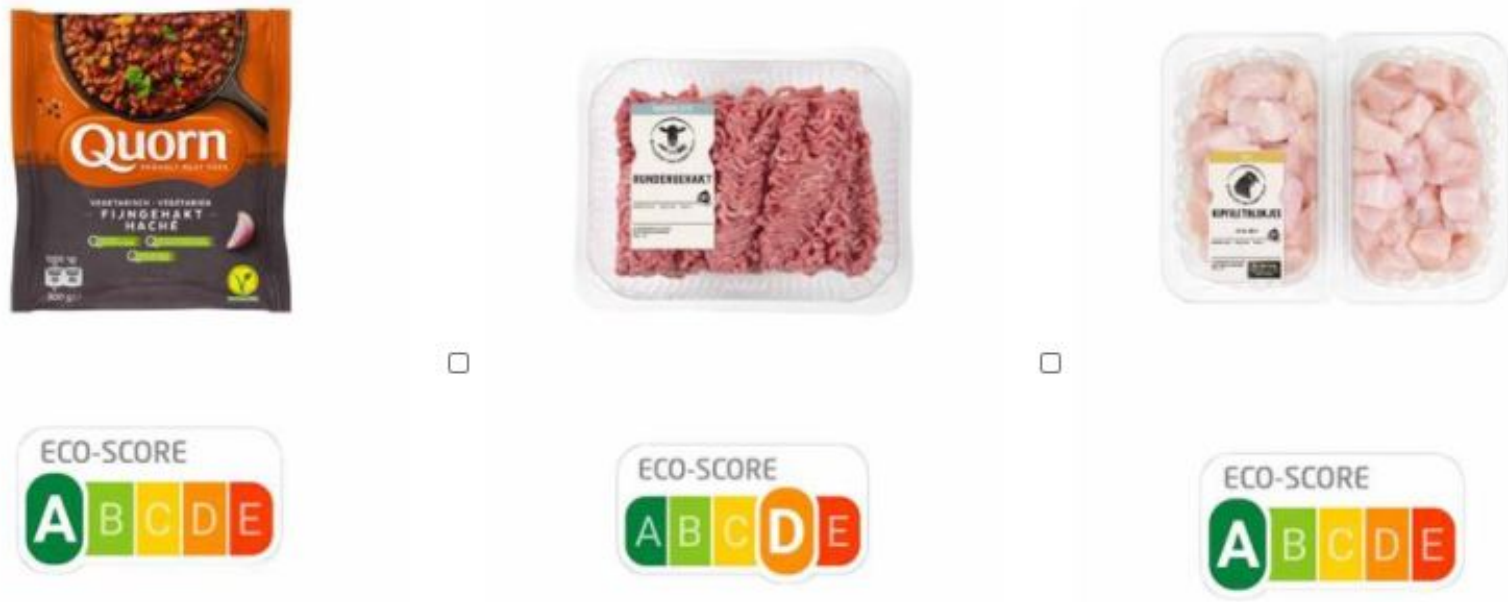

Minced vegetarian meat $300 \mathrm{~g}-\mathbf{\epsilon} .38$

Minced beef $500 \mathrm{~g}-€ 3.69$

Chicken (without skin) $2 \times 300 \mathrm{~g}-€ 5.00$
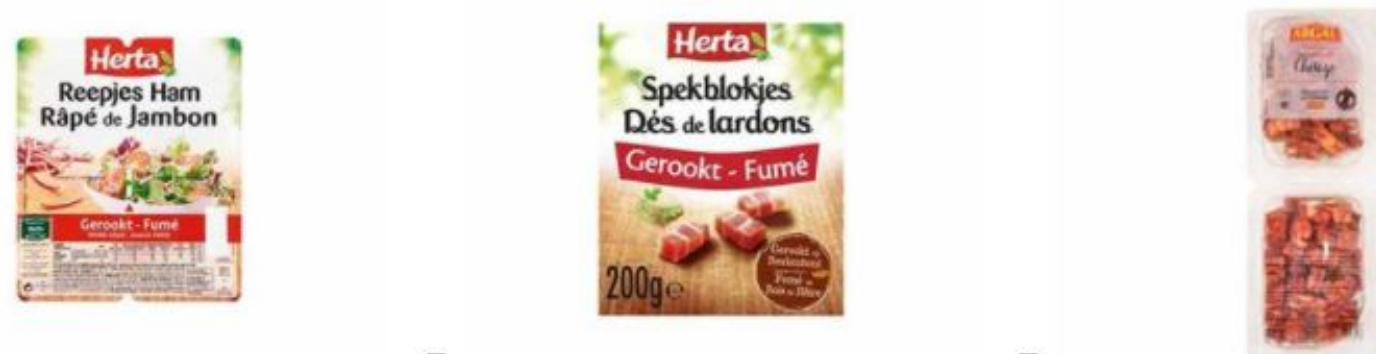

ECO-SCORE

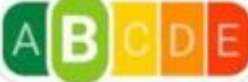

ECO-SCORE

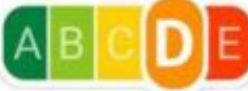

ECO-SCORE

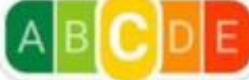

Smoked ham $2 \times 75 g-€ 3.59$

Bacon 200g - $€ 3.05$

Chorizo $2 \times 50 \mathrm{~g}-€ 1.89$

Figure A2. Cont. 

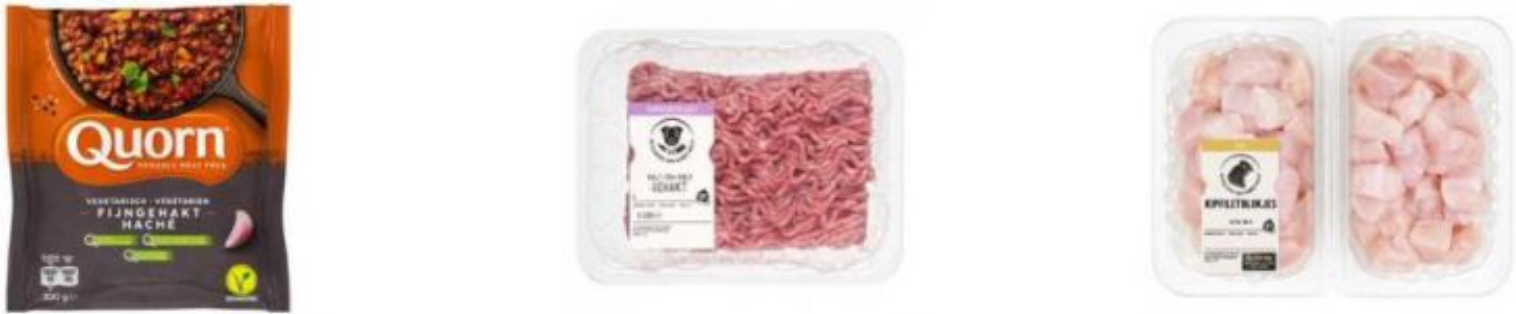

Per 1009

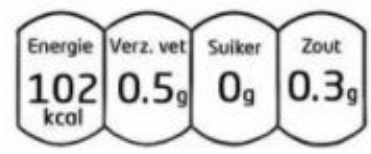

Minced vegetarian meat $300 \mathrm{~g}-€ 3.38$

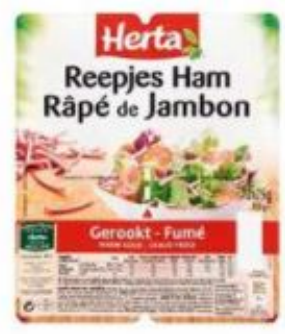

Per $100 \mathrm{~g}$

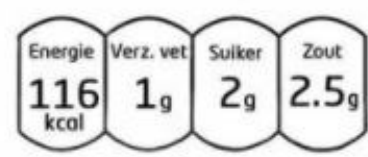

Smoked ham 2x75g - $\mathbf{\epsilon 3 . 5 9}$
Per 1009

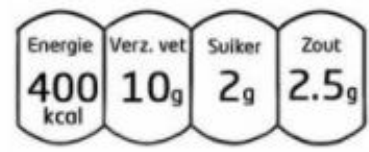

Minced beef $500 \mathrm{~g}$ - $€ 3.69$

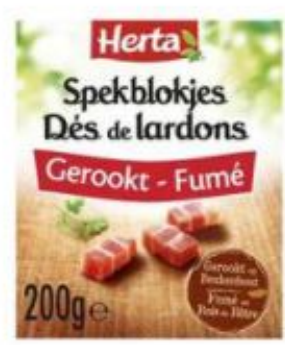

Per $100 \mathrm{~g}$

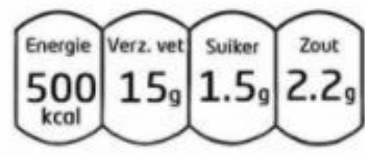

Bacon $200 \mathrm{~g}-€ 3.05$

Chorizo $2 \times 50 \mathrm{~g}-€ 1.89$
Per $100 \mathrm{~g}$

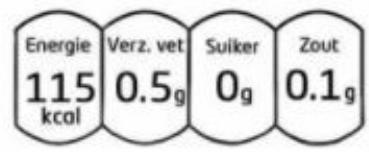

Chicken (without skin) $2 \times 300 \mathrm{~g}-£ 5.00$

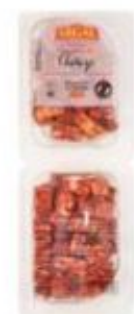

Per 100g

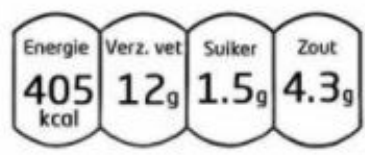

Figure A2. Cont. 


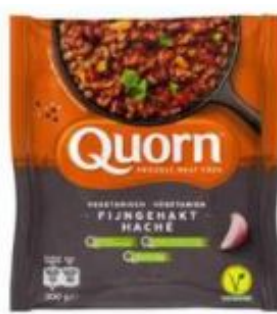

Per $100 \mathrm{~g}$

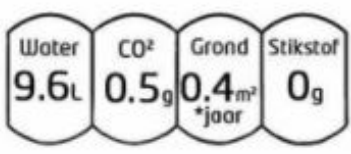

Minced vegetarian meat $300 \mathrm{~g}-\mathbf{€ 3 . 3 8}$

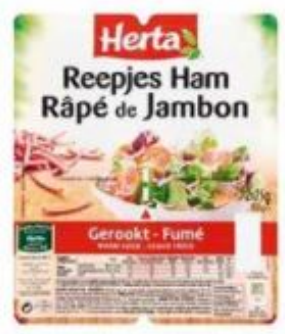

Per 100g

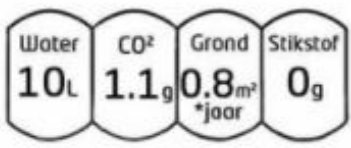

Smoked ham $2 \times 75 g$ - $€ 3.59$
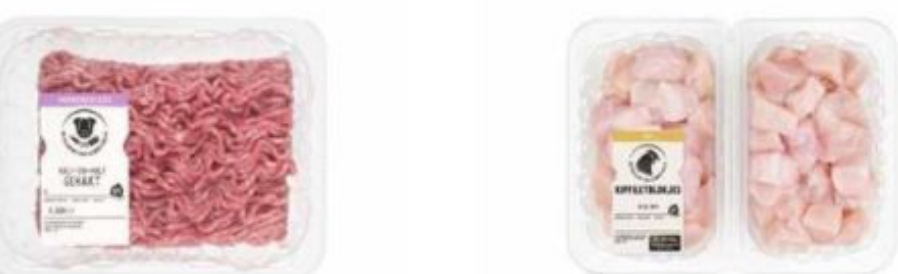

Per $100 \mathrm{~g}$

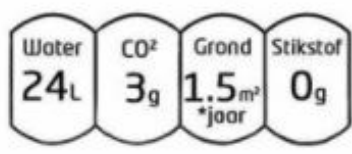

Per $100 \mathrm{~g}$

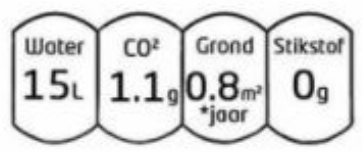

Minced beef $500 \mathrm{~g}-€ 3.69$

Chicken (without skin) $2 \times 300 \mathrm{~g}-€ 5.00$

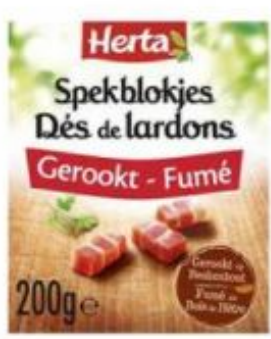

Per $100 \mathrm{~g}$

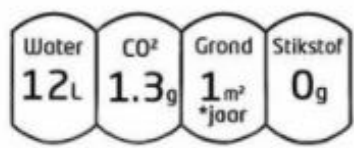

Per $100 \mathrm{~g}$

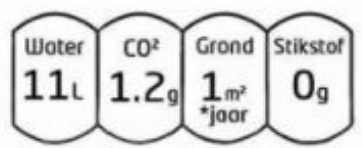

Chorizo $2 \times 50 \mathrm{~g}$ - $€ 1.89$

Figure A2. Cont. 


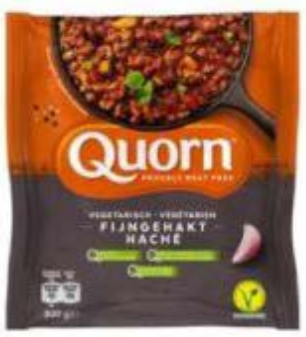

Minced vegetarian meat $300 \mathrm{~g} \cdot \mathbf{\epsilon} .38$
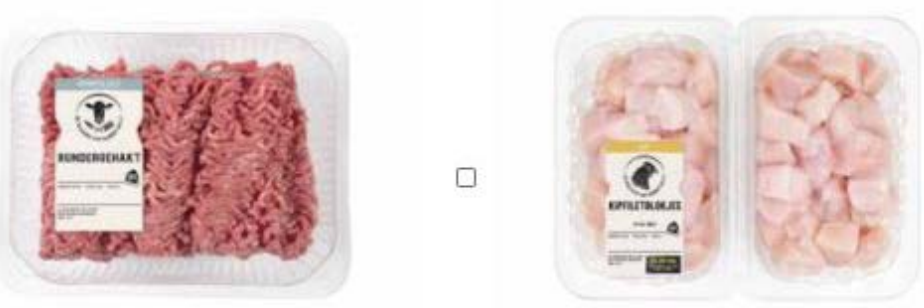

Minced beef $500 \mathrm{~g}-€ 3.69$

Chicken (without skin) $2 \times 300 \mathrm{~g}-€ 5.00$

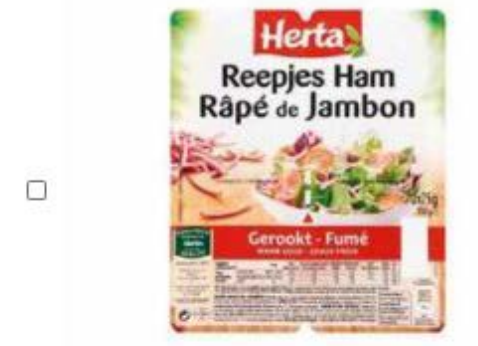

Smoked ham $2 \times 75 g$ - $\mathbf{6 3 . 5 9}$

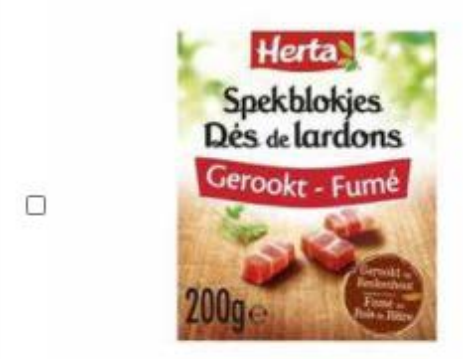

Bacon $200 \mathrm{~g}-€ 3.05$

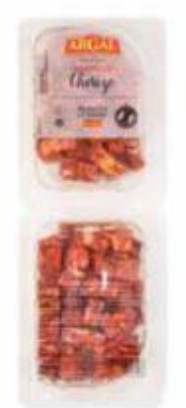

Chorizo $2 \times 50 \mathrm{~g}-€ 1.89$

Figure A2. Example of web shop stimuli across different conditions in Study 2.

\section{References}

1. Ritchie, H.; Roser, M. Environmental Impacts of Food Production. Available online: https://ourworldindata.org/environmentalimpacts-of-food\#citation (accessed on 17 November 2020).

2. Westhoek, H.; Lesschen, J.P.; Rood, T.; Wagner, S.; De Marco, A.; Murphy-Bokern, D.; Leip, A.; van Grinsven, H.; Sutton, M.A.; Oenema, O. Food Choices, Health and Environment: Effects of Cutting Europe's Meat and Dairy Intake. Glob. Environ. Chang. 2014, 26, 196-205. [CrossRef]

3. Willett, W.; Rockström, J.; Loken, B.; Springmann, M.; Lang, T.; Vermeulen, S.; Garnett, T.; Tilman, D.; DeClerck, F.; Wood, A.; et al. Food in the Anthropocene: The EAT_Lancet Commission on Healthy Diets from Sustainable Food Systems. Lancet 2019, 393, 447-492. [CrossRef]

4. Aleksandrowicz, L.; Green, R.; Joy, E.J.M.; Smith, P.; Haines, A. The Impacts of Dietary Change on Greenhouse Gas Emissions, Land Use, Water Use, and Health: A Systematic Review. PLoS ONE 2016, 11, e0165797. [CrossRef]

5. European Commission. Special Eurobarometer 468; European Commission: Brussels, Belgium, 2017.

6. Hughner, R.S.; McDonagh, P.; Prothero, A.; Shultz, C.J.; Stanton, J. Who Are Organic Food Consumers? A Compilation and Review of Why People Purchase Organic Food. J. Consum. Behav. 2007, 6, 94-110. [CrossRef]

7. Testa, F.; Iraldo, F.; Vaccari, A.; Ferrari, E. Why Eco-Labels Can Be Effective Marketing Tools: Evidence from a Study on Italian Consumers. Bus. Strategy Environ. 2015, 24, 252-265. [CrossRef]

8. European Environmental Agency. Food Consumption: Animal Based Protein. Available online: https://www.eea.europa.eu/ airs/2018/resource-efficiency-and-low-carbon-economy/food-consumption-animal-based (accessed on 9 December 2020).

9. Birt, C.; Buzeti, T.; Grosso, G.; Justesen, L.; Lachat, C.; Lafranconi, A.; Mertanen, E.; Rangelov, N.; Sarlio-Lähteenkorva, S. Healthy and Sustainable Diets for European Countries. Available online: https:/ / eupha.org/repository/advocacy/EUPHA_report_on_ healthy_and_sustainable_diets_20-05-2017.pdf (accessed on 24 August 2020).

10. Milford, A.B.; Le Mouël, C.; Bodirsky, B.L.; Rolinski, S. Drivers of Meat Consumption. Appetite 2019, 141, 104313. [CrossRef] [PubMed] 
11. Goossens, Y.; Berrens, P.; Charleer, L.; Coremans, P.; Houbrechts, M.; Vervaet, C.; De Tavernier, J.; Geeraerd, A. Qualitative Assessment of Eco-Labels on Fresh Produce in Flanders (Belgium) Highlights a Potential Intention-Performance Gap for the Supply Chain. J. Clean. Prod. 2017, 140, 986-995. [CrossRef]

12. Vermeir, I.; Verbeke, W. Sustainable Food Consumption: Exploring the Consumer "Attitude-Behavioral Intention" Gap. J. Agric. Environ. Ethics Dordr. 2006, 19, 169-194. [CrossRef]

13. Symmank, C.; Mai, R.; Hoffmann, S.; Stok, F.M.; Renner, B.; Lien, N.; Rohm, H. Predictors of Food Decision Making: A Systematic Interdisciplinary Mapping (SIM) Review. Appetite 2017, 110, 25-35. [CrossRef] [PubMed]

14. Nardi, V.A.M.; Jardim, W.C.; Ladeira, W.; Santini, F. Predicting Food Choice: A Meta-Analysis Based on the Theory of Planned Behavior. Br. Food J. 2019, 121, 2250-2264. [CrossRef]

15. Gatersleben, B.; Murtagh, N.; Abrahamse, W. Values, Identity and pro-Environmental Behaviour. Contemp. Soc. Sci. 2014, 9 , 374-392. [CrossRef]

16. Molinario, E.; Lorenzi, C.; Bartoccioni, F.; Perucchini, P.; Bobeth, S.; Colléony, A.; Diniz, R.; Eklund, A.; Jaeger, C.; Kibbe, A.; et al. From Childhood Nature Experiences to Adult Pro-Environmental Behaviors: An Explanatory Model of Sustainable Food Consumption. Environ. Educ. Res. 2020, 26, 1137-1163. [CrossRef]

17. Çoker, E.N.; van der Linden, S. Fleshing out the Theory of Planned of Behavior: Meat Consumption as an Environmentally Significant Behavior. Curr. Psychol. 2020. [CrossRef]

18. Verain, M.C.D.; Sijtsema, S.J.; Antonides, G. Consumer Segmentation Based on Food-Category Attribute Importance: The Relation with Healthiness and Sustainability Perceptions. Food Qual. Prefer. 2016, 48, 99-106. [CrossRef]

19. Siegrist, M.; Hartmann, C. Impact of Sustainability Perception on Consumption of Organic Meat and Meat Substitutes. Appetite 2019, 132, 196-202. [CrossRef] [PubMed]

20. Wunderlich, S.; Gatto, K.A. Consumers' Food Choices and the Role of Perceived Environmental Impact. Int. J. Sustain. Dev. Plan. Southampt. 2016, 11, 989-995. [CrossRef]

21. Ungemach, C.; Camilleri, A.R.; Johnson, E.J.; Larrick, R.P.; Weber, E.U. Translated Attributes as Choice Architecture: Aligning Objectives and Choices Through Decision Signposts. Manag. Sci. 2017, 64, 2445-2459. [CrossRef]

22. Hartikainen, H.; Roininen, T.; Katajajuuri, J.-M.; Pulkkinen, H. Finnish Consumer Perceptions of Carbon Footprints and Carbon Labelling of Food Products. J. Clean. Prod. 2014, 73, 285-293. [CrossRef]

23. Macdiarmid, J.I.; Douglas, F.; Campbell, J. Eating like There's No Tomorrow: Public Awareness of the Environmental Impact of Food and Reluctance to Eat Less Meat as Part of a Sustainable Diet. Appetite 2016, 96, 487-493. [CrossRef] [PubMed]

24. Camilleri, A.R.; Larrick, R.P.; Hossain, S.; Patino-Echeverri, D. Consumers Underestimate the Emissions Associated with Food but Are Aided by Labels. Nat. Clim. Chang. 2019, 9, 53-58. [CrossRef]

25. Hallez, L.; Qutteina, Y.; Raedschelders, M.; Boen, F.; Smits, T. That's My Cue to Eat: A Systematic Review of the Persuasiveness of Front-of-Pack Cues on Food Packages for Children vs. Adults. Nutrients 2020, 12, 1062. [CrossRef] [PubMed]

26. Vlaams Instituut Gezond Leven. Nutri-Score I Gezond Leven. Available online: https://www.gezondleven.be/themas/voeding/ beleid/voedingslabels/nutri-score-label (accessed on 6 December 2020).

27. Szabo de Edelenyi, F.; Egnell, M.; Galan, P.; Druesne-Pecollo, N.; Hercberg, S.; Julia, C. Ability of the Nutri-Score Front-of-Pack Nutrition Label to Discriminate the Nutritional Quality of Foods in the German Food Market and Consistency with Nutritional Recommendations. Arch. Public Health 2019, 77, 28. [CrossRef] [PubMed]

28. De Temmerman, J.; Heeremans, E.; Slabbinck, H.; Vermeir, I. The Impact of the Nutri-Score Nutrition Label on Perceived Healthiness and Purchase Intentions. Appetite 2020, 104995. [CrossRef] [PubMed]

29. Egnell, M.; Talati, Z.; Hercberg, S.; Pettigrew, S.; Julia, C. Objective Understanding of Front-of-Package Nutrition Labels: An International Comparative Experimental Study across 12 Countries. Nutrients 2018, 10, 1542. [CrossRef] [PubMed]

30. Borzan, B.; Rivasi, M.; Trillet-Lenoir, V.; Goyens, M.; van Hevel, D.; Bazot, A.; Pirrone, A.; King, O.; Balhanas, A.; Mechels, I.; et al. Joint Letter to the European Commission Re: Mandatory Nutri-Score; Commissioner for Health and Food Safety, European Commission: Brussels, Belgium, 2020.

31. European Commission. Food Information to Consumers-Legislation. Available online: https://ec.europa.eu/food/safety/ labelling_nutrition/labelling_legislation_en (accessed on 14 January 2021).

32. Bialkova, S.; Grunert, K.G.; van Trijp, H. From Desktop to Supermarket Shelf: Eye-Tracking Exploration on Consumer Attention and Choice. Food Qual. Prefer. 2020, 81, 103839. [CrossRef]

33. Hawley, K.L.; Roberto, C.A.; Bragg, M.A.; Liu, P.J.; Schwartz, M.B.; Brownell, K.D. The Science on Front-of-Package Food Labels Public Health Nutr. 2013, 16, 430-439. [CrossRef] [PubMed]

34. Ecolabel Index All Ecolabels. Available online: http:/ / www.ecolabelindex.com/ecolabels/ (accessed on 21 August 2020).

35. Prag, A.; Lyon, T.; Russillo, A. Multiplication of Environmental Labelling and Information Schemes (ELIS): Implications for Environment and Trade. Available online: https://www.oecd-ilibrary.org/environment/multiplication-of-environmentallabelling-and-information-schemes-elis_5jm0p33z27wf-en (accessed on 20 August 2020).

36. European Commission. The Organic Logo. Available online: https://ec.europa.eu/info/food-farming-fisheries/farming/ organic-farming/organic-logo_en (accessed on 14 January 2021).

37. Engels, S.V.; Hansmann, R.; Scholz, R.W. Toward a Sustainability Label for Food Products: An Analysis of Experts' and Consumers' Acceptance. Ecol. Food Nutr. 2010, 49, 30-60. [CrossRef] [PubMed] 
38. Taufique, K.M.R.; Vocino, A.; Polonsky, M.J. The Influence of Eco-Label Knowledge and Trust on pro-Environmental Consumer Behaviour in an Emerging Market. J. Strateg. Mark. 2017, 25, 511-529. [CrossRef]

39. Vlaeminck, P.; Jiang, T.; Vranken, L. Food Labeling and Eco-Friendly Consumption: Experimental Evidence from a Belgian Supermarket. Ecol. Econ. 2014, 108, 180-190. [CrossRef]

40. Clement, J.; Kristensen, T.; Grønhaug, K. Understanding Consumers' in-Store Visual Perception: The Influence of Package Design Features on Visual Attention. J. Retail. Consum. Serv. 2013, 20, 234-239. [CrossRef]

41. Muller, L.; Lacroix, A.; Ruffieux, B. Environmental Labelling and Consumption Changes: A Food Choice Experiment. Environ. Resour. Econ. Dordr. 2019, 73, 871-897. [CrossRef]

42. Vanclay, J.K.; Shortiss, J.; Aulsebrook, S.; Gillespie, A.M.; Howell, B.C.; Johanni, R.; Maher, M.J.; Mitchell, K.M.; Stewart, M.D.; Yates, J. Customer Response to Carbon Labelling of Groceries. J. Consum. Policy Dordr. 2011, 34, 153-160. [CrossRef]

43. Atkinson, L.; Rosenthal, S. Signaling the Green Sell: The Influence of Eco-Label Source, Argument Specificity, and Product Involvement on Consumer Trust. J. Advert. 2014, 43, 33-45. [CrossRef]

44. Aertsens, J.; Verbeke, W.; Mondelaers, K.; Huylenbroeck, G.V. Personal Determinants of Organic Food Consumption: A Review. Br. Food J. Bradf. 2009, 111, 1140-1167. [CrossRef]

45. Test Aankoop Peiling Test Aankoop: Meerderheid Consumenten Gewonnen Voor een Verplichte Nutri-Score. Available online: https:/ / www.test-aankoop.be/action/persinformatie/persberichten/2020/peiling-nutri-score (accessed on 10 December 2020).

46. Delhaize Belgium E-Shop Startpagina. Available online: https://www.delhaize.be/nl-be/shop/Naar-de-e-shop/c/v2WEB (accessed on 13 December 2020).

47. Schau, E.M.; Fet, A.M. LCA Studies of Food Products as Background for Environmental Product Declarations. Int. J. Life Cycle Assess. 2008, 13, 255-264. [CrossRef]

48. Thøgersen, J.; Haugaard, P.; Olesen, A. Consumer Responses to Ecolabels. Eur. J. Mark. Bradf. 2010, 44, 1787-1810. [CrossRef]

49. Howse, E.; Hankey, C.; Allman-Farinelli, M.; Bauman, A.; Freeman, B. Buying Salad Is a Lot More Expensive than Going to McDonalds: Young Adults' Views about What Influences Their Food Choices. Nutrients 2018, 10, 996. [CrossRef]

50. Food and Agricultural Organization of the United Nations. Biodiversity and Sustainable Diets. 2010. Available online: http: //www.fao.org/ag/humannutrition/29186-021e012ff2db1b0eb6f6228e1d98c806a.pdf (accessed on 19 January 2021).

51. Rijksinstituut Voor Volksgezondheid en Milieu Milieubelasting Voedingsmiddelen. Available online: https://statline.rivm.nl/\#/ $\mathrm{RIVM} / \mathrm{nl} /$ dataset/50060NED/table?ts=1594119197916 (accessed on 26 August 2020).

52. Dutta-Bergman, M.J. Health Attitudes, Health Cognitions, and Health Behaviors among Internet Health Information Seekers: Population-Based Survey. J. Med. Internet Res. 2004, 6, e15. [CrossRef] [PubMed]

53. Graham, T.; Abrahamse, W. Communicating the Climate Impacts of Meat Consumption: The Effect of Values and Message Framing. Glob. Environ. Chang. 2017, 44, 98-108. [CrossRef]

54. de Groot, J.; Steg, L. Value Orientations to Explain Beliefs Related to Environmental Significant BehaviorHow to Measure Egoistic, Altruistic, and Biospheric Value Orientations. Environ. Behav. 2008, 40, 330-354. [CrossRef]

55. Hess, R.; Visschers, V.H.; Siegrist, M. The Role of Health-Related, Motivational and Sociodemographic Aspects in Predicting Food Label Use: A Comprehensive Study. Public Health Nutr. 2012, 15, 407-414. [CrossRef] [PubMed]

56. Satia, J.A.; Galanko, J.A.; Neuhouser, M.L. Food Nutrition Label Use Is Associated with Demographic, Behavioral, and Psychosocial Factors and Dietary Intake among African Americans in North Carolina. J. Am. Diet. Assoc. 2005, 105, $392-402$. [CrossRef] [PubMed]

57. Bacon, L.; Krpan, D. (Not) Eating for the Environment: The Impact of Restaurant Menu Design on Vegetarian Food Choice. Appetite 2018, 125, 190-200. [CrossRef] [PubMed]

58. Statista Belgium: Share of Vegans and Vegetarians, by Region 2018. Available online: https://www.statista.com/statistics/8075 67/vegans-and-vegetarians-in-belgium-by-region/ (accessed on 4 December 2020).

59. Carbonneau, E.; Lamarche, B.; Provencher, V.; Desroches, S.; Robitaille, J.; Vohl, M.-C.; Bégin, C.; Bélanger, M.; Couillard, C.; Pelletier, L.; et al. Associations Between Nutrition Knowledge and Overall Diet Quality: The Moderating Role of Sociodemographic Characteristics-Results From the PREDISE Study. Am. J. Health Promot. 2020, 0890117120928877. [CrossRef] [PubMed]

60. Feunekes, G.I.J.; Gortemaker, I.A.; Willems, A.A.; Lion, R.; van den Kommer, M. Front-of-Pack Nutrition Labelling: Testing Effectiveness of Different Nutrition Labelling Formats Front-of-Pack in Four European Countries. Appetite 2008, 50, 57-70. [CrossRef] [PubMed]

61. Ducrot, P.; Julia, C.; Méjean, C.; Kesse-Guyot, E.; Touvier, M.; Fezeu, L.K.; Hercberg, S.; Péneau, S. Impact of Different Front-of-Pack Nutrition Labels on Consumer Purchasing Intentions: A Randomized Controlled Trial. Am. J. Prev. Med. 2016, 50, 627-636. [CrossRef]

62. Méjean, C.; Macouillard, P.; Péneau, S.; Hercberg, S.; Castetbon, K. Perception of Front-of-Pack Labels According to Social Characteristics, Nutritional Knowledge and Food Purchasing Habits. Public Health Nutr. 2013, 16, 392-402. [CrossRef] [PubMed]

63. Poquet, D.; Ginon, E.; Goubel, B.; Chabanet, C.; Marette, S.; Issanchou, S.; Monnery-Patris, S. Impact of a Front-of-Pack Nutritional Traffic-Light Label on the Nutritional Quality and the Hedonic Value of Mid-Afternoon Snacks Chosen by Mother-Child Dyads. Appetite 2019, 143, 104425. [CrossRef] [PubMed]

64. Grolleau, G.; Ibanez, L.; Mzoughi, N.; Teisl, M. Helping Eco-Labels to Fulfil Their Promises. Clim. Policy 2016, 16, 792-802. [CrossRef]

65. Tobi, R.C.A.; Harris, F.; Rana, R.; Brown, K.A.; Quaife, M.; Green, R. Sustainable Diet Dimensions. Comparing Consumer Preference for Nutrition, Environmental and Social Responsibility Food Labelling: A Systematic Review. Sustainability 2019, 11, 6575. [CrossRef] 
66. Mahmood, K. Do People Overestimate Their Information Literacy Skills? A Systematic Review of Empirical Evidence on the Dunning-Kruger Effect. Commun. Inf. Lit. 2016, 10, 199-213. [CrossRef]

67. Loeber, S.; Grosshans, M.; Herpertz, S.; Kiefer, F.; Herpertz, S.C. Hunger Modulates Behavioral Disinhibition and Attention Allocation to Food-Associated Cues in Normal-Weight Controls. Appetite 2013, 71, 32-39. [CrossRef] [PubMed]

68. Moreno-Padilla, M.; Fernández-Serrano, M.J.; Reyes del Paso, G.A. Risky Decision-Making after Exposure to a Food-Choice Task in Excess Weight Adolescents: Relationships with Reward-Related Impulsivity and Hunger. PLoS ONE 2018, 13, e0202994. [CrossRef] [PubMed]

69. Loewenstein, G. Out of Control: Visceral Influences on Behavior. Organ. Behav. Hum. Decis. Process. 1996, 65, 272-292. [CrossRef]

70. US Department of Agriculture (USDA). Save More at the Store I ChooseMyPlate. Available online: https://www.choosemyplate. gov / eathealthy/budget/budget-save-more (accessed on 27 November 2020).

71. Nayga, R.M. Nutrition Knowledge, Gender, and Food Label Use. J. Consum. Aff. 2000, 34, 97-112. [CrossRef]

72. Huyghe, E.; Verstraeten, J.; Geuens, M.; Van Kerckhove, A. Clicks as a Healthy Alternative to Bricks: How Online Grocery Shopping Reduces Vice Purchases. J. Mark. Res. 2017, 54, 61-74. [CrossRef]

73. Crosetto, P.; Lacroix, A.; Muller, L.; Ruffieux, B. Nutritional and Economic Impact of 5 Alternative Front-of-Pack Nutritional Labels: Experimental Evidence. Available online: https://hal.archives-ouvertes.fr/hal-01805431/document (accessed on 13 February 2021).

74. Grolleau, G.; Mzoughi, N.; Sutan, A. Does Advertising the Green Benefits of Products Contribute to Sustainable Development Goals? A Quasi-Experimental Test of the Dilution Effect. Bus. Strategy Environ. 2019, 28, 786-793. [CrossRef] 